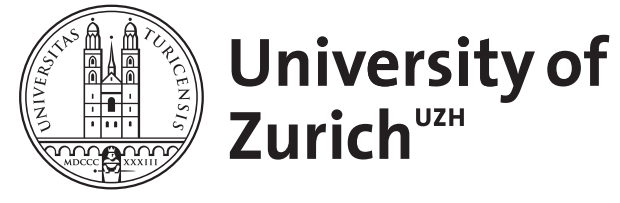

\title{
Don't be afraid! Persuasive Practices in the Wild
}

\author{
Dolata, Mateusz ; Schwabe, Gerhard
}

\begin{abstract}
Advisory service encounters evolve from providing expertise to joint problem-solving. Additionally, advisees depend on persuasion, which drives them to follow the advisor's recommendations. However, advisors can be insufficiently equipped to persuade, resulting in advisees who are incapable of action or are unmotivated. Persuasive technology (PT) research proves that technology can motivate and enable people in single-user scenarios but pays limited attention to the natural realm of persuasion: the face-to-face conversation. This paper explores how persuasive technology transforms advice giving, a collaborative scenario involving an expert and a layperson. In such scenarios, IT does not act as a persuader but can provide affordances for persuasive practices, i.e., suggest new practices or enhance existing ones for convincing the advisee without deception or enforcement. We investigate the advisory practices in 24 real burglary prevention service encounters supported by IT. The paper shows the persuasive practices emerging through appropriation of the system, the tensions that govern the adoption or transformation of specific practices and routines and it confirms that studying the use and appropriation of technology uncovers organizational conflicts and tensions affecting such fundamental aspects as the advisor's role and job description. Keywords Advisory practices Advisory services Appropriation Burglary Crime prevention Motivation and ability Persuasive practices Persuasive technology Practice theory
\end{abstract}

DOI: https://doi.org/10.1007/s10606-018-9330-4

Posted at the Zurich Open Repository and Archive, University of Zurich

ZORA URL: https://doi.org/10.5167/uzh-160721

Journal Article

Accepted Version

Originally published at:

Dolata, Mateusz; Schwabe, Gerhard (2018). Don't be afraid! Persuasive Practices in the Wild. Computer Supported Cooperative Work, 27(3-6):427-462.

DOI: https://doi.org/10.1007/s10606-018-9330-4 


\title{
Don't be afraid! Persuasive Practices in the Wild
}

\author{
Mateusz Dolata ${ }^{\bowtie}$, Gerhard Schwabe \\ Department of Informatics, University of Zurich \\ \{dolata,schwabe\}@ifi.uzh.ch
}

\begin{abstract}
Advisory service encounters evolve from providing expertise to joint problemsolving. Additionally, advisees depend on persuasion, which drives them to follow the advisor's recommendations. However, advisors can be insufficiently equipped to persuade, resulting in advisees who are incapable of action or are unmotivated. Persuasive technology (PT) research proves that technology can motivate and enable people in singleuser scenarios but pays limited attention to the natural realm of persuasion: the face-toface conversation. This paper explores how persuasive technology transforms advice giving, a collaborative scenario involving an expert and a layperson. In such scenarios, IT does not act as a persuader but can provide affordances for persuasive practices, i.e., suggest new practices or enhance existing ones for convincing the advisee without deception or enforcement. We investigate the advisory practices in 24 real burglary prevention service encounters supported by IT. The paper shows the persuasive practices emerging through appropriation of the system, the tensions that govern the adoption or transformation of specific practices and routines and it confirms that studying the use and appropriation of technology uncovers organizational conflicts and tensions affecting such fundamental aspects as the advisor's role and job description.
\end{abstract}

Keywords: advisory practices, advisory services, appropriation, burglary, crime prevention, motivation and ability, persuasive practices, persuasive technology, practice theory 


\section{Introduction}

Advisory service encounters rapidly change their character: whereas in the past, an advisee primarily expected the provision of essential information, the available solution options and suggestions, he ${ }^{1}$ now enters an advisory service equipped with diverse evidence and opinions from online sources (Bouwman et al., 2010; Escarrabill et al., 2011; Leune and Nizard, 2012). An advisee who learns several contradictory opinions on the Internet may be confused and establish misleading preconceptions and expectations about the outcome of an advisory service. Those biases negatively influence utilization of the advice and, often, the quality of the decision (Yaniv, 2004b; Yaniv, 2004a). It can have a particularly detrimental effect if a patient disregards advice from a doctor and alters his treatment on his own or if a potential crime victim ignores police suggestions on how to keep safe (Swindell et al., 2010). Similar problems may also occur in other similar kinds of beneficent advice-giving, i.e., in advisory services oriented towards the advisee's wellbeing without monetary incentives on the advisor's side, if the advisor fails to address ineffective biases of the advisee, heuristics and preconceptions. Therefore, persuasion, i.e. interpersonal influence without deception or coercion, has the potential to enhance this specific class of counselling service. Additionally, the field of persuasive technology promises to leverage new mobile and multimedia technologies in order to enhance persuasiveness in various single-user scenarios (Fogg, 2009; Anderson and Agarwal, 2010; Oinas-Kukkonen, 2010; Park et al., 2014). Knowledge concerning the application of persuasive technologies in collaborative scenarios remains rudimentary and concentrates on distributed collaboration (Yang and Kraut, 2017). We know little about supporting persuasion with technology in a co-located scenario: in particular, we lack understanding on how persuasive technology impacts the highly sensitive social relationship in a colocated scenario and how the users will appropriate this technology given its potential impacts. This study develops a systematic understanding of practices that emerge through application of persuasive technology in real beneficent advisory encounters. It points to social, organizational and individual preconditions that form the advisors' persuasion routines in addition to the technology and situative context. It thereby expands on previous studies on persuasive practices conducted in the laboratory (Dolata et al., 2016; Dolata and Schwabe, 2017a) and on the technological support of co-located collaboration in advisory service encounters (Novak and Schmidt, 2009; Heinrich et al., 2014).

The study presented was entangled in the last phase of a research project on supporting burglary prevention advisors in their daily work. In the burglary prevention (BP) scenario, police trained in technical security visit residents at their homes to advise them on how to secure their properties against burglary

\footnotetext{
${ }^{1}$ For simple gender balance and for clarity of the argument, we refer to the advisor (police officer) as a female (she, her) and to the advisee (citizen) as a male (he, his).
} 
(Giesbrecht et al., 2015; Comes and Schwabe, 2016a; Comes and Schwabe, 2016b). The public mandate of police crime prevention units includes, among others, promoting the implementation of crime prevention measures and enabling communities to prevent burglary cases from happening. BP advisors act upon this task; however, they often lack systematic training for it. Depending on their career, they rely on an introductory hands-on training, general police officer schooling, exposure to burglary or crime cases in their previous appointments (e.g., during patrol or investigator duties), as well as experience from previous advisory encounters, and their technical expertise. Prone to influence by the complex nature of interpersonal communication, they differ significantly in how they motivate or enable their advisees and, as this study unveils, how they shape their task during this communication. Some focus on transferring the message: "don't be afraid!", whereas others exaggerate stories from criminal statistics. After the roll-out of the SmartProtector, a tablet-based tool designed according to persuasive technology guidelines to support a range of persuasive practices, the differences between the various advisors emerged. Each advisor favoured a stockpile of routines (stories, arguments, explanations, etc.) which were activated based on their preconceptions and observations about the advisee, the local or situational circumstances and the private perception of the advisor's task. This study makes clear that behaviours that were originally considered a mundane part of a conversation (e.g., a story from the neighbourhood), could be recognized as an essential and routinized persuasive device. The SmartProtector was appropriated as far as it could be meaningfully applied in the routines. This sheds new light on the persuasive aspect of the work: it grows out of a range of conversational routines and is not like a debate with explicit arguments or targeted behaviours. Consequently, supporting persuasion is less about extending the persuasive arsenal with technology but rather about equipping IT with a meaning that fits the stories, explanations, and narratives the advisors used to provide, and about affording new behaviours that may turn into routines. Overall, this study proposes the picture of persuasive practices as routines originating as strong stereotypes, as well as the advisor's opinion towards ongoing organizational discourses and tensions. Transforming those practices with IT requires consideration of multiple cues about the situation and its background rather than an optimistic assumption about the improvisational character of practices. The current study arrived at those insights by pursuing the following research questions:

- What are persuasive practices and how do they manifest themselves in advisory encounters?

- How do advisors appropriate persuasive technology in advisory encounters?

To answer these questions, we embed the study in a project conducted with four different police agencies in two countries, involving 9 local police departments and 18 BP advisors. The project was originally launched to specify the design of the SmartProtector in a user-centred process involving the advisors, advisees and police BP experts/managers. In the last phase of the project, the SmartProtector was 
rolled out for use by the advisors for at least six months. A researcher accompanied nine advisors to $24 \mathrm{BP}$ advisory sessions and collected notes, as well as audio recordings, which form the data basis for the current analysis.

\section{Related work}

\subsection{Studying Practices in CSCW}

A practice perspective on work activities has been characteristic for the computersupported cooperative work (CSCW) community for decades (Kuutti and Bannon, 2014). While rooted in self-reflective and programmatic discussion in social sciences (Nicolini, 2012), the practice lens on human activities has been adopted to elaborate on use and appropriation of IT artefacts in the CSCW (Schmidt and Bannon, 2013; Kuutti and Bannon, 2014) and information systems (IS) (Orlikowski, 2008). Currently, the artefact-oriented research on work practice moves from laboratory settings towards "in-the-wild" studies using ethnomethodologically-informed methods. The usage of artefacts occurs in real social and material contexts between real stakeholders and outgrows the human, physical nature of interaction (Dourish, 2001). However, as study of practices in the field is costly in terms of time and labour, large areas of real work practice remain underexplored (Wulf et al., 2011). This study addresses the area of advisory service encounters, which leaves numerous urgent issues open: what advisory practices exist and what advisory practices emerge through introduction of digital artefacts.

Practice-oriented research in the CSCW pays special attention to the transformative nature of practices (Wulf et al., 2011). More specifically, CSCW has a long tradition of "designing for practices", those which already exist in the work context and those which may emerge through the introduction of an artefact (Schmidt, 2011). Consequently, researchers observe and evaluate what practices emerge in the field, whether they reflect the practices intended in the design of the artefact, and whether the support is as effective as expected (Wulf et al., 2011; Kuutti and Bannon, 2014) while following the situated-action perspective (Suchman, 1987; Orlikowski, 2008). The technology appropriation research discusses factors influencing the actual use of IT (Orlikowski and Iacono, 2001; Dourish, 2003; Orlikowski, 2008; Stevens et al., 2010; Salovaara et al., 2011; Dourish, 2013) and identifies patterns of use for artefact classes (Richter and Riemer, 2009). The current study acknowledges the fact that practices resulting from appropriation of a technology have, to some extent, an improvisational character (Orlikowski, 2008). However, it takes as its source the insight that routines and routinized behaviours strongly impact the conversations between people (Schegloff, 1986). Since the advisory encounters have a strong social 
character and, at least for the advisor, are highly repetitive, the routines are likely to form an essential structure for driving appropriation of the IT. We therefore conceptualize practices as seeable, indigenous actions that participants directly engage in, but do not focus on in an analytic manner (Garfinkel, 1967; Nicolini, 2012). They are settled behaviours and interactional devices which have an internal, implicit order which gets re-enacted in interactions with other people and within the context of the action (Schegloff, 1986; Wooffitt, 2005). Given this description of practices, transformation of practices poses a serious challenge: routinized behaviours are persistent and depend on automatic processing of information rather than rational decisions (Kahneman, 2011). Nevertheless, they often possess a more or less implicit rationale, a driver that lets them emerge in specific situations (Schegloff, 1986; Scollon, 2001). In particular, direct interactions with other people rely strongly on such routines driven by various rationales: from simply keeping the conversation going to more advanced rationales like receiving information or receiving acknowledgement (Schegloff, 1986; Wooffitt, 2005). Also, routinized behaviours typical for advisory services, i.e., advisory practices, have their specific rationales including rapport building (Heinrich et al., 2014), impression management (Dolata and Schwabe, 2017c), or contextualizing the recommendation (Fischer et al., 2017). However, specifying and describing this rationale is not straightforward, since the obvious masks the implicit: most advisors define their work as providing a recommendation (Schwabe and Nussbaumer, 2009). It remains unclear what the typical practices characteristic for beneficent advisory practices are, what rationales drive the advisors' engagement in those practices and how transformation works in this context.

Dialectics offers a particular lens to observe and analyse routinized behaviours and approaches to transform them in a work context, including the technologydriven transformation of work practices. It was used particularly successfully in organizational change and innovation research to study how organizations develop when new systems are introduced (Fidock and Carroll, 2010). Dialectics describes forces and tensions that rule a particular social phenomenon and therefore allows the systematic identification of what drives a group of social agents to establish contrary behaviours: it points to opposite forces that may be hidden for the sake of conserving the social order and harmony in an organization (Ven and Poole, 1995). Dialectics sees tensions as antithetical, antagonistic relations between contrary forces that an individual needs to balance out (Fidock and Carroll, 2010). Whereas the lens seems appropriate for studying cases where technology appropriation leads to various, contradictory practices, only a few studies make use of it (Myers, 1995; Cho and Mathiassen, 2007; Carlo et al., 2012), and if they do, they focus on tensions between the organization and an individual. We propose the dialectic perspective for studying and explaining situations, where the observed subjects (in our case, the advisors) systematically and repeatedly engage in practices that essentially differ from each other, not only concerning individual performance (e.g., advisors 
formulating their question in different ways) but also the advisor's explanation for the rationale behind their performance when confronted with the difference. This follows Scollon's (2001) view, which accentuates that a practice expresses political, societal and organizational discourses, apart from being a situated performance. This adds to the routine-based practices' definition introduced above: the routines do not only follow the rationales and current, situative cues, but they incorporate social and organizational discourses. Since the design of any artefact cannot be agnostic towards the way it gets enacted in practice (i.e., it affords some practices, but not others) and towards organizationally or politically-motivated rationale, this approach seems appropriate for studying digital transformation of practices. Particularly, some practices will emerge in line with the technology design, while others emerge in spite of the affordances of the system, action offerings, and spirit. A spirit (DeSanctis and Poole, 1994) or a set of intended practices (Wulf et al., 2011) can originate from multiple sources (project team's vision, product owner's vision, key user's vision, etc.), but only the confrontation with real world use allows its validation. The dialectic of giving beneficent advice elaborated later in this manuscript represents, therefore, a polemic between the contrary values of various user groups but incorporates the fact that some values and structures were more compatible with the practices envisioned and intended in the SmartProtector's design.

\subsection{Supporting Advisory Services and Advisory Practices}

Advisory services pose a specific form of collaboration which involve an advisor and an advisee. From the service-science perspective they form a high-touch point of contact between the service provider and the service customer with potential for intensifying the relationship (Jungermann, 1999; Vargo and Akaka, 2012). From the conversation studies perspective, they are a specific form of institutional talk, i.e., interaction where both interlocutors have their typical organizational identities and act upon them while employing language, materials and body accordingly (Drew and Heritage, 1992; Svennevig, 2001; Svinhufvud and Vehviläinen, 2013). From the collaboration support (including $\mathrm{CSCW}$ ) perspective, they are a specific form of collaboration between two protagonists who may differ concerning their goals and knowledge states (Heinrich et al., 2014; Heyman and Artman, 2015; Fischer et al., 2017). For instance, advisory services are modeled as rational problem solving where solution follow from an analysis of the situation and available facts in a stepwise deduction and optimization process (Simon, 1978; Comes and Schwabe, 2016a). The various perspectives on advisory services stress their complex character and the extraordinary role of the subtle, interpersonal dimension, which is typical for collaboration that happens only occasionally between strangers (Drew and Heritage, 1992; Heinrich et al., 2014). Similarly, they stress the fact that advisory encounters rely heavily on the stereotypes advisees and 
advisors have about what happens and what should happen in those encounters (Jungermann, 1999; Svinhufvud and Vehviläinen, 2013). Consequently, advisory encounters have generated significant interest in the CSCW and IS communities, thus leading to valuable insights about the role of the material (Dolata and Schwabe, 2017c), face gaze (Heinrich et al., 2014), and data (Fischer et al., 2017) therein.

Currently, advisory services are undergoing an intensive phase of transformation. The changes are driven by technology entering the encounters, expectations of the customers, as well as by the easy, on-line access to information, which was previously available only to experts (Schwabe and Nussbaumer, 2009; Dolata and Schwabe, 2017b). Due to this transformation, the main focus of advisory services moves from information provision and recommendation to joint problem solving (Dolata and Schwabe, 2017b). This is reflected in the emergence of new advisory practices (Dolata and Schwabe, 2017c; Dolata and Schwabe, 2017a; Fischer et al., 2017). For instance, energy advisors involve the advisee during the analysis of specific, individual data for providing a suitable recommendation rather than generic suggestions (Fischer et al., 2017). Similarly, bank advisors try to learn and document many aspects of an advisee's life, while asking typical questions, to offer an individualized rather than a standard, off-theshelf package (Kilic et al., 2017). The advisory practices encompass situative, improvisational elements (Fischer et al., 2014; Fischer et al., 2017), as well as routinized behaviours and conversational strategies (Dolata and Schwabe, 2017c; Dolata and Schwabe, 2017a; Kilic et al., 2017). For example, in a BP advisory service, an advisor may routinely suggest a specific rim door lock with a bolt and present its working mechanism with a specimen; however this behavior will emerge if the door explicitly requires such a lock or the advisor notices that the advisee uses a (potentially insecure) chain lock (Dolata et al., 2016). Given the fact that the advisory practices combine routinized and situative behaviour, and considering the ongoing transformation of advisory services, this field offers a range of relevant research questions: What is the main point of an advisory service if not the information transfer between an expert and a layperson? How can IT support new practices that outgrow previously existing routines? How should IT take account of the situative character or situative activation of some practices?

Previous research positions technology in advisory encounters as a shared artefact of focus (Novak, 2009), an ad-hoc provider of specific information or context (Heyman and Artman, 2015; Fischer et al., 2017), a tool to develop an advisor's skill on the job (Giesbrecht et al., 2016), or a motivational device through enhancement of the hedonic qualities of interpersonal interaction (Novak and Schmidt, 2009). The IT artefact deployed in the current study, SmartProtector, borrows from previously existing tools in several ways, while extending their potential to afford persuasion in interpersonal encounters (Comes and Schwabe, 2016b; Comes and Schwabe, 2016a). Thereby, the system answers the increasing need for supporting attitude or behaviour change in the advisee. In particular, we 
encounter essential shifts in what doctors need to do during their medical services: due to patients being 'prepared' by looking up their symptoms on-line, doctors are increasingly involved in persuasive efforts by reassuring or rejecting patient narratives, proposing their own opinions, or engaging the patient in self-diagnosis (Zucchermaglio et al., 2016). In such and similar contexts, including BP, the persuasion happens in between, irregularly, without explicit character and often without consideration of the advisee's biases or presuppositions (Yaniv and Kleinberger, 2000; Yaniv, 2004b; Swindell et al., 2010). In other words, the advisor does not normally try to identify what bias may impact the advisee, but routinely and intuitively employs means to convince him: whether the advisee fails, due to the anchoring effect (the first information found seems most plausible) or confimation bias (selecting cues based on their concordance with pre-existing beliefs), does not play a large role (Swindell et al., 2010). This may lead to unsystematic and ineffective behaviours in the advisor, who may, e.g., approach a decision in a purely logical manner, while the advisee's decision is purely emotional. The authors adhere to the general assumption, that persuasion may enhance the qualitiy of advisory services in many areas. Not only the public agencies want to enhance effectiveness of service encounter, but also the advisees increasingly seek a clear recommendation support them at dealing with the confusion and information overload ${ }^{2}$. IT could enhance the persuasive character of advisory encounters (Comes and Schwabe, 2016b); however, it remains open as to whether and how the advisors would employ it in practice: would they be receptive to the possibility of persuasion provided by a system? How would they use it?

\subsection{Persuasive Technology and Persuasive Practices}

Persuasion has been traditionally defined as "human communication designed to influence the autonomous judgments and actions of others" (Simons and Jones, 2011), or, alternatively, as "a successful intentional effort at influencing another's mental state through communication in a circumstance in which the persuadee has some measure of freedom" (O'Keefe, 2002). Normally, the persuader appeals to the persuadee's human drive, mental state and cognitive abilities (O'Keefe, 2002; Cialdini, 2007; Simons and Jones, 2011) and the persuadee does or does not change her own behaviour and attitudes, i.e., produces a specific response to the persuasive effort (Cialdini, 2007). Persuasive practices were previously framed as a persuader's routinized actions conducted to reinforce, change or shape a persuadee's attitudes or behaviours without deception or coercion (Dolata et al., 2016). While normally these practices emerge organically, through experience and

2 Discussion of the political dimensions of open or implicit persuasion especially in light of the existence of such units as Social and Behavioral Sciences Team under the Obama administration (Kahneman, 2011), goes beyond the scope of this article. We adhere to the standpoint, that persuasion efforts are legitimate as long as they follow persuadee's interest and exclude deceipt or coercion of any kind. 
on-the-job training (Swindell et al., 2010), recent experimental and conceptual research shows that they may also emerge through enactment of structures provided by an IT artefact (Dolata et al., 2016). Nevertheless, we still lack knowledge about the persuasive practices, as they emerge in the wild and how IT may form them or not; given the complex nature of practices encompassing routinized and situational elements, as well as political and organizational discourses. This manuscript explores persuasive practices and their manifestation in an ongoing collaborative effort: to what extent is IT-supported persuasion a routine? To what extent is it an improvisational achievement? How does it depend on the larger social and organizational context?

Persuasion as a type of human-to-human communication has been widely considered in psychology literature yielding a number of models to explain how people respond to persuasive effort (Chaiken, 1980; Chaiken, 1987; Petty, 2013). Persuasive Technology (PT) employs this knowledge to propose IT-based persuasion in the following single-user scenario settings: computer-human influence, computer-mediated human-human influence, and computer-moderated human-human influence (Stibe, 2015). PT has not considered the persuader as an individual in the cooperative situation (Oinas-Kukkonen and Harjumaa, 2009; Oinas-Kukkonen, 2010; Stibe and Oinas-Kukkonen, 2014; Stibe, 2015). Instead, PT explores designs which produce a persuasive effect; thereby, it relies on the model for persuasive design proposed by Fogg (2009), who claims that IT shall (1) enable the persuadee to tackle the issue by explicating what effort is needed to reach the target state, (2) motivate the persuadee through rejection of the current state and emotional discomfort related to it, and (3) trigger her to act, i.e., facilitate the change of behaviour and attitude at the right moment. This model was shown to be compatible with the psychological background and was later extended to a socio-technical model (Oinas-Kukkonen and Harjumaa, 2009). Only recently, PT has acknowledged the potential for application in collaborative settings, where persuasive design can assist the persuader at enabling and motivating the persuadee in an advisory scenario or in a team collaboration (Dolata et al., 2016; Yang and Kraut, 2017). However, the transfer or design guidelines from a single-user scenario to a collaborative scenario pose essential challenges: what is the role of the technology? Does it take over the role of persuader (while the person remains a collaborator or an advisor) or does it afford persuasion? What/who assesses the need to enhance the persuasive effort - the technology or the persuader? Who assesses what the appropriate target for the persuasion is?

PT has traditionally addressed domains where the persuadee has clear objectives and the PT supports a particular way of reaching the goal (losing weight through a combination of sport and healthy food or giving up smoking by reducing the number of cigarettes per day). An advisory context and, in particular, BP poses a challenge, because the ultimate target (e.g., being secured against burglary) is more abstract than the above and does not generate a coherent, concrete picture of the 
future, but is rather a wish. Ways to reach the state are also unclear for two reasons: (1) while almost everyone knows (or claims to know) what to do to lose weight, it is not common knowledge how to prevent burglary, (2) while losing weight or giving up cigarettes primarily involves behaviour changes (which are at the heart of PT according to Fogg (2009)), preventing burglary often requires changes of attitude such as maintenance of fear (Gabriel and Greve, 2003; Barberet and Fisher, 2009). Criminology literature suggests that, in crime prevention, enabling relates to the education of individuals and communities about the crime and about adequate safety precautions to enhance the self-efficacy of the potential victims (Ozer and Bandura, 1990; Davis and Smith, 1994; Madero-Hernandez et al., 2016), whereas motivating embraces moderating the fear of crime to a level which is unpleasant to the potential victims (and activates them), but without making them too afraid to manage or enjoy their life (Erete, 2013; Bernasco, 2014; MaderoHernandez et al., 2016). Overall, research relating to persuasion and technology provides valuable insights on the nature of persuasion and indicates that it can be engineered. However, its focus so far has been on single-user scenarios, so that we know only little about how following PT guidelines can change persuasive practices in advisory services.

\section{Artefact Description}

The SmartProtector was designed in a user-centred process. The advisors' requirements were collected through observation of two key users in their daily work in 2012, followed by workshops in 2013, and later during the design of working prototypes. They were tested in simulation experiments with various BP advisors from Switzerland and Germany in the years 2013, 2014, 2015, and 2016 (Giesbrecht et al., 2015; Comes and Schwabe, 2016a; Comes and Schwabe, 2016b). The police management requirements and suggestions were collected in interviews and workshops throughout the project. They primarily wanted to improve the adherence to advice among advisees to reduce the number of successful burglaries. Advisors stressed the importance of rapport building and the need for reducing the overheads of formalities relating to setting up and documentation of an advisory service on-site and later in their office. The SmartProtector was designed to support the overall performance of a BP advisory service and, in addition, afford the persuasive practices proposed by the stakeholders and supported by the literature. In the following, we summarize the affordances and their expected effect on the advisor's practices.

Supporting a Rational Process: the SmartProtector implements (but does not enforce) an advisory approach, which felt most natural to the key users. Through the graphical representation of the tool's main menu (Figure 1), advisors are encouraged to engage in a process which begins with information about the house (protection object), followed by the identification and discussion of the advisee's 
most urgent and important protection needs. Then, the advisor and the advisee explore the property to identify security flaws and elaborate on them. Finally, they develop a security plan combining all the proposed solutions into a coherent action plan. This represents the routines of all key users from the design phase.

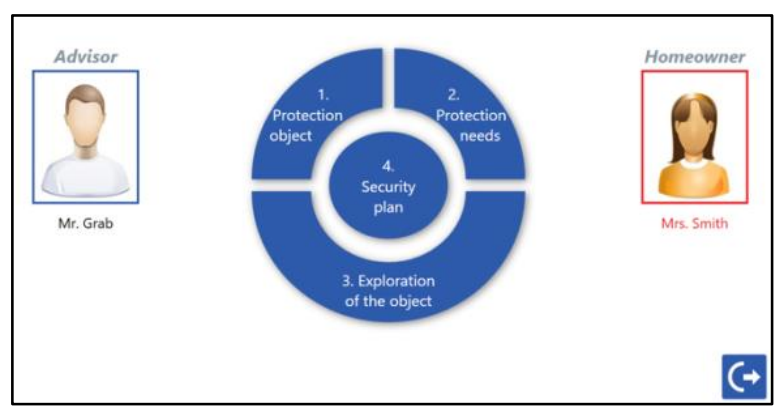

Figure 1. The SmartProtector's process navigation screen.

Identifying Protection Needs: to afford an actual discussion of advisee needs, the SmartProtector provides a list of the most frequent advisee needs (Figure 2 left). The explicit mentioning of the advisee's needs should help him and the advisor address and maintain his fears and offer space for emotional messages.

Separating and Linking Problem and Solution: during exploration of the object, the advisor and the advisee discuss various security flaws. By separating problem and solution areas for each security flaw, the SmartProtector affords (1) specification of the current situation and why it poses a security problem (Figure 2 - right) as well as (2) the choice of an adequate technical, electronic, behavioural solution and explanation of why it fits the given situation. Since the problem and the solution are linked to the same item, they also remain linked to each other. This empowers the advisee to single out the diagnosis concerning an item (e.g., $a$ window or a locking mechanism) and the rationale behind the proposed solution (e.g., a grid as opposed to an alarm because of the required cellar ventilation).
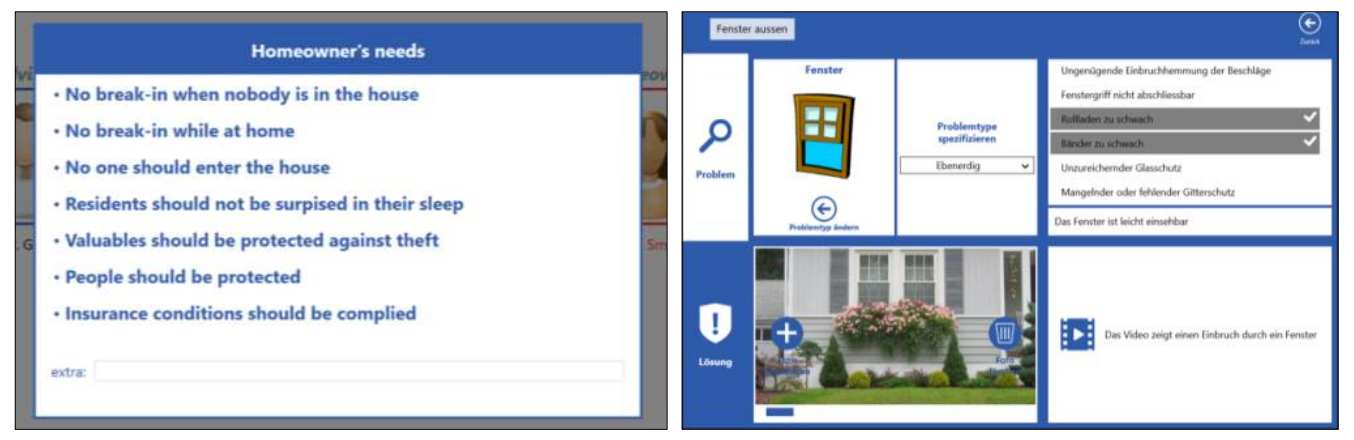

Figure 2. Left: The protection needs screen; Right: The problem specification screen.

Specifying Problem and Solution: to describe a security flaw as a problem, the advisor can define what element is problematic (e.g., window in the cellar); he can 
characterize how it is a security issue (e.g., easy to reach and weak hinges); he can take a photograph of the object and use markings to illustrate the critical points (Figure 3 - left); and he can use a video to make clear to the advisee how a similar window could be used by a burglar to break in. Similarly, the tool provides ways to characterize the solution: the advisor can choose from and discuss all relevant technical (e.g., grids, hinges, locks), electronic (e.g., alarms, surveillance cameras), and behavioural (e.g., habits, tricks) solutions from her organizational database; she can illustrate them with pictures, schemata or videos; finally, she can choose the appropriate ones to flow into a security plan. The design concerning the problem and solution dimensions is in line with the general rational problem-solving approach, but it also provides access to vivid multimedia material to afford emotionally loaded messages when describing the issues and proposing solutions.
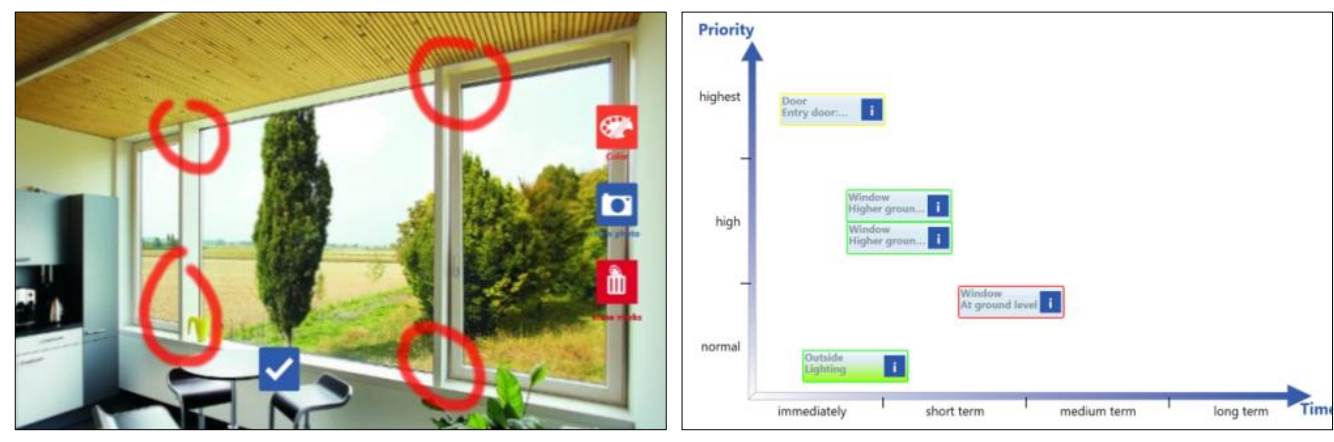

Figure 3. Left: The picture taking and sketching screen; Right: The prioritizing issues screen.

Composing an Action Plan: the security plan summarizes the security flaws identified earlier, suited to the collected needs of the advisee. The plan will also provide means for the advisor and the advisee for a collaborative combination of the proposed solutions into a coherent plan for action. Traditionally, advisors summarized their recommendations verbally, by writing down a random list of suggestions, or by marking suggested solutions in brochures. The SmartProtector answers the requests from the practitioners by affording classification and prioritization of the proposed solutions (Figure 3 - right).

Overall, the design of SmartProtector offers several practices, which have a motivating or an enabling character. They should enhance the persuasive character of the encounter, as demanded by police managers and advisors, and as claimed by the literature. The experiments conducted throughout the project show that the advisors (following training or guidance in experimental settings) respond positively to the affordances and see the potential improvements resulting from new or transformed practices. Also, the analysis of test advisee feedback suggests that the practices have the expected motivating or enabling effect (Giesbrecht et al., 2015; Comes and Schwabe, 2016a; Comes and Schwabe, 2016b). However, the impact of the SmartProtector on real advisory services remained unclear. 


\section{Methodology}

The study aims to observe real work practices which emerged during appropriation of SmartProtector. Therefore, this study essentially differs from past experimentbased studies (e.g., Dolata et al., 2016). The observation was embedded in a development and roll-out project with four police agencies (two from Germany, two from Switzerland). The project started in 2012, but the data collection happened only in the last phase. The roll-out of SmartProtector for daily use by the advisors was carefully prepared: the advisors received training on the SmartProtector's usage and the use scenarios implied in the design. They also had the opportunity to try it out in experimental sessions and simulations with test advisees.

This manuscript uses data collected during a longitudinal field study in June and August 2016. An observer accompanied nine randomly selected advisors during their visits to clients' houses, on their way between the appointments, and during preparation and post processing. The advisors selected had all used SmartProtector in at least 10 service encounters before participating in this study. Overall, the observer visited 24 advisory sessions conducted by advisors using the system. For security reasons, only little demographic data about advisees was collected, but from the type of property and from what was recounted in the advisory service, the observer can deduce that they mostly belonged to the middle class. Around a half of all services were conducted in flats, the other half in single-family houses. The professions of the advisees included a farmer, a teacher, office clerks and retired persons. All properties, except for one, were used by at least two persons (mostly a couple with or without children). Since the advisory sessions focus on securityrelevant issues and affect private and intimate topics, extensive audio or video recording forms a security risk and was not possible. The primary mode of data collection was chronological note-taking: the notes describe the interaction between the participants, primary conversation topics and general argumentation structure, as well as interaction with tools and objects. Material produced during the advisory sessions (anonymized documentation) was used to complement the notes. Voice recording was used to capture formal and informal conversations between the observer and each of the advisors, where they reviewed specific events from the sessions. As SmartProtector had been successfully used over 1250 times during the pilot run (without technical support from the developer or the researcher), we claim that it had reached the popularity and maturity of a productive system and permitted observation of "settled" practices. Additionally, the study uses information collected in the form of audio-recordings from three workshops conducted in June and September 2016 for triangulation purposes. Parts of the workshops were conducted only with the advisors; other parts included their managers too. Eight managers participated in the workshops; they were invited to participate for two reasons: they initiated the roll-out of SmartProtector and were 
curious about the advisors' opinions, and they represented the organizations' opinion in the discussions. Each workshop participant (advisors as well as their managers) had an interview of approximately 45 minutes.

The research team addressed data coherence: (1) all observations were made by a single researcher who did not directly participate in the development of the SmartProtector (2) the observer collected data in a short and recent time period (3) all advisors used the same version of the system with the same functionality (4) all advisors met the observer not less than three but not more than five times before the observation (5) all advisors and advisees agreed freely to the observation (6) each advisor participated in at least two observations.

The observations of 24 advisory sessions, recordings of informal and formal discussions with the advisors after those sessions, and the whole-day workshops described above provide the following data set: 185 pages of observer's notes in B5 format, approximately 70 hours of audio recordings from discussions and workshops, and 264 sheets of paper, including drawings or written comments from the workshops. The collected data was digitalized. For the analysis, we followed a two-tier process: first, the observer, under the supervision of two other experienced researchers, structured, iteratively coded and grouped the heterogeneous data according to their chronological order and thereby prepared the practices listed in the results. The coding applied in this phase was reflected the advisors process steps (hence the structure of the respective section in Results), the usage of the tool's features and the intention of the practice as declared by the advisor in the interview. Second, the researchers analysed opinions collected during workshops and in conversations used to explain the advisors' view.

\section{Results}

Generally, advisors follow a three-tier process starting with a preliminary examination of the building, including the immediate neighbourhood, an introductory discussion with the advisee, and then they explore the property, including the garden or staircase, if necessary; finally, they summarize the service encounter. The core elements of the process are surrounded by small talk initiated by either of the parties. The discussion has a mainly natural character but security remains the focus, even during small talk.

\subsection{Protection Object and Protection Needs}

Advisors give the advisee the opportunity to introduce their needs by asking questions like those in Table $1(a, b, c)$. Some questions are more open and invite a wider-ranging contribution ( $a$ or $c$ ), while others have a closed character to identify two kinds of advisee $(b)$. Similarly, discussion of the advisee's response can have a more open and explorative character $(d)$, be a review of cases or 
burglars' tactics, which confirms justified or contravenes unjustified advisee fears ( $e$ or $f$ ), or simply close the discussion $(g)$. Sometimes, an answer to the closed question $b$ was followed by no essential reaction $(g)$ and the advisor moved on to exploration of the property. The SmartProtector was intended for use as a common artefact for discussing a set of "standard fears" and focusing the advisee on the ones which are legitimate, given the recent advisory cases and burglars' tactics, and invalidating those which are irrational and reduce the advisee's feeling of wellbeing. However, it was used that way in only the minority of cases. In other cases, the advisor noted the needs while holding the tablet as a private artefact of work (without sharing the screen with the advisee) or simply omitted this point altogether. Excerpt 1 one illustrates an advisor asking an open question while using the SmartProtector as an excuse; she positions the tool as a common artefact and discusses the advisee's statement while referring to burglar tactics.

Table 1. Practices applied when discussing protection needs ( $\mathrm{P}$ - police officer, $\mathrm{C}$ - citizen).

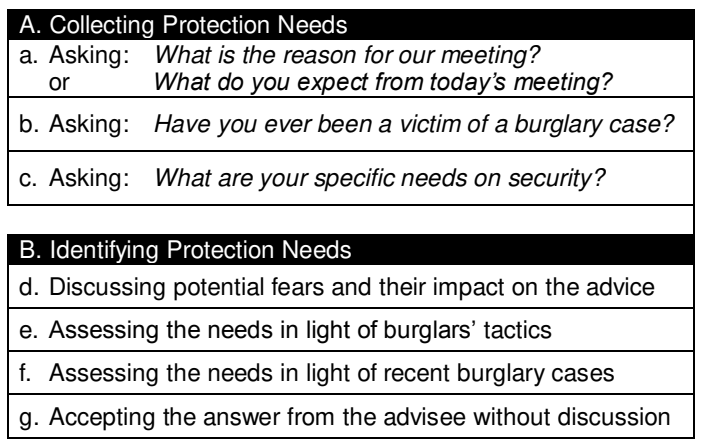

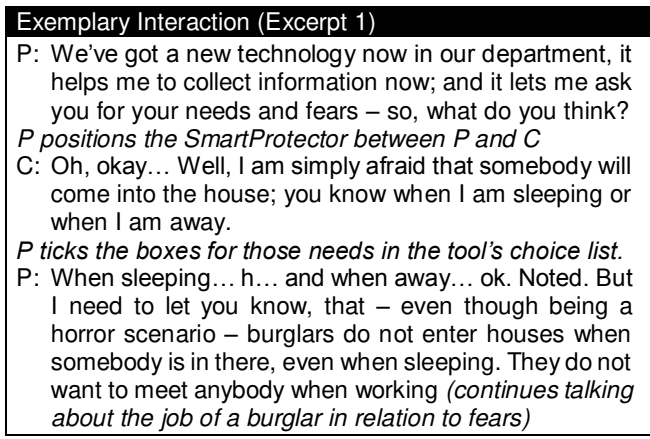

View of advisors and management: advisors provide three explanations for diverging from the identification of protection needs: (1) They feel uneasy asking the advisee about their fears. The advisors claim that the advisees are not aware of any fears at the beginning of the advisory session or, on the contrary, all advisees have the same fears. (2) the advisors primarily want to teach the advisee something new, so they present what they know best (i.e., burglary strategies). (3) the advisors see themselves as technical and not behavioural BP experts. An advisor assumes the behaviour of advisees to be primarily rational and knowledge oriented: "People only approach us if the fundamental will to be convinced is already there. People already want to change something, but they just do not really know what they need to change". Nevertheless, some advisors systematically engage in discussing the advisee's needs and fears and they build upon that to explain the differences between burglary and robbery, clarify the likelihood of those crimes and explain the criminals' motives, and, if necessary, moderate the fear of crime if the advisee misinterprets news or societal changes. They also make clear how the advice will address their credible fears. An advisor says: "No matter if they implement something afterwards or not, for me the advice has already been successful when I realize that the fears can be taken or channelled, that one can deal better with the 
fears". Another advisor presented a screwdriver (i.e., a tool, burglars use in the vast majority of cases) each time he was discussing the fears in relation to burglar tactics. He explains: "I use it in almost all my advisory sessions to show how little is required to break in, but also to make clear that a burglar is not prepared to kill or harm people or is in anyway equipped to do so (...) I also draw the house with the percentage [of listed burglary incidents per floor] to capture and direct their fears. This is what I do by default, regularly, so I keep my knowledge of statistics updated." Those BP managers interviewed see it as part of a police officer's job to enter into dialogue with the public and listen to people's expectations. Considering the persuasive character of the encounter, some managers would go as far as defining the success of an encounter by assessing how it manages advisee security needs and fears and whether it can employ them for activating the advisee: "So we want to sensitize and motivate and give responsibility to the citizen, such that he can do something about the fears and not remain passive while saying 'I hope this does not happen to me'. But that he becomes aware of the fact that he can actively do something about it (...). We see ourselves as a service provider to the citizen." Overall, some advisors see it as an essential part of their work to motivate the advisee by harnessing their needs for change and fear of crime for motivation ( $a, c$, $d$ ), while others stress the role of the objective, and generally applicable information $(b, e, f)$ and discount the individual character of the advisees' security needs. An advisor explains what he says when entering an advisory service: "Do not be angry with me, I'm a police officer, I'm totally impartial. I do not speak for or against a state government. I'll give you information here and I'll leave it to you, how you rate it".

\subsection{Exploration of the Object}

Whenever the advisor encounters a security issue that potentially may be used by a burglar to break in, she points out the security flaw to the advisee (Table 2). While some advisors systematically explain why and how a security flaw is a problem (either because it can be leveraged by a burglar $-j$, or because it does not fit the advisee's needs and habits $-k$ ), others limit themselves to a general assessment of the item under consideration $(i)$ or declare it to be a problem because a specific solution they already have in mind (e.g., a grid) is missing $(h)$. The same can be observed in the sketches advisors create during the exploration phase. Some advisors mark problematic areas or weak elements, while others generate sketches of the solution to be installed (even though the SmartProtector provides schematic solution pictures). The SmartProtector was designed to afford a general definition of the problem, accompanied by its illustration, and an explanation of why it is a problem given that burglary is a negative event $(j)$ - the latter can be supported with the videos provided. 
After identifying an issue, the advisor proposes an adequate solution. If they have specified the problem they can build upon it, while explaining how the solution they propose improves the situation. However, some advisors systematically engage in very exact explanations of the mechanics of the solution. Moreover, some even employ a specimen (which can weigh up to one kilogram, e.g., a window locking mechanism) or an exact sketch they drew ( $l$ or $n)$, accompanied by an outline from the SmartProtector $(m)$, and interaction with the considered item through gesticulation $(o)$. However, other advisors limit themselves to roughly defining the solution $(o)$ and may present a picture $(m)$. The SmartProtector affords an exploration of the possible solutions followed by the choice of the most appropriate one(s). If the advisor spends a lot of time and resources explaining a single solution, discussing others may not be an option. Furthermore, some advisees may be overwhelmed by the technical details.

Table 2. Practices applied for discussion of the security flaws ( $\mathrm{P}$ - police officer, $\mathrm{C}-$ citizen $)$

\begin{tabular}{|c|}
\hline h. Indicating that a security improvement is missing \\
\hline Providing assessment of a feature as "insufficient" \\
\hline $\begin{array}{l}\text { j. Illustrating how a burglar might leverage the current weak } \\
\text { point for breaking in }\end{array}$ \\
\hline $\begin{array}{l}\text { k. Clarifying why present security solutions are incompatible } \\
\text { with the advisee's needs and habits }\end{array}$ \\
\hline D. Proposing solutions for the security flaw \\
\hline I. Presenting a specimen of the proposed solution \\
\hline m. Presenting a picture of the proposed solution \\
\hline n. Creating a sketch of the proposed solution \\
\hline $\begin{array}{l}\text { o. Illustrating the proposed solution through gesture and } \\
\text { speech only }\end{array}$ \\
\hline Exemplary Interaction (Excerpt 2) \\
\hline $\begin{array}{l}\text { P: How old is this house? Are the windows new? } \\
P \text { looks at the window frame and touches elements of the } \\
\text { locking mechanism with the fingers (top, bottom, side). } \\
\text { C: Hmmm... They're maybe } 10 \text { years old. I don't remember. } \\
\text { P: You've got a weak locking mechanism, I must say. It uses } \\
\text { just a single mushroom bolt to secure the downside of the } \\
\text { window, while the others are simple rods. It has been a } \\
\text { standard for years. Try to feel it with your hand down here. } \\
P \text { takes C's hand and places it first on the mushroom bolt, } \\
\text { then on the rods at the side of the window. C nods, } \\
\text { mumbles. P scrolls on the tablet and positions it between } \\
C \text { and P. } \\
\text { P: A burglar can open a window like this within seconds, } \\
\text { because the rods just slip over the catch in the frame. Have } \\
\text { a look at this picture. You see the difference, right? } \\
P \text { points to a schema in SmartProtector showing the bolt and } \\
\text { the rod and turns her finger as if she was blocking the one } \\
\text { and the other, and pretends to apply force to the imaginary } \\
\text { bolt represented just by the picture on the tablet } \\
\text { P: And here l've got a video to show to you - it's almost exactly } \\
\text { your window; you see, the burglar uses a simple } \\
\text { screwdriver and he's inside there just within few seconds. } \\
P \text { and } C \text { watch a video on SmartProtector, C nods. }\end{array}$ \\
\hline
\end{tabular}

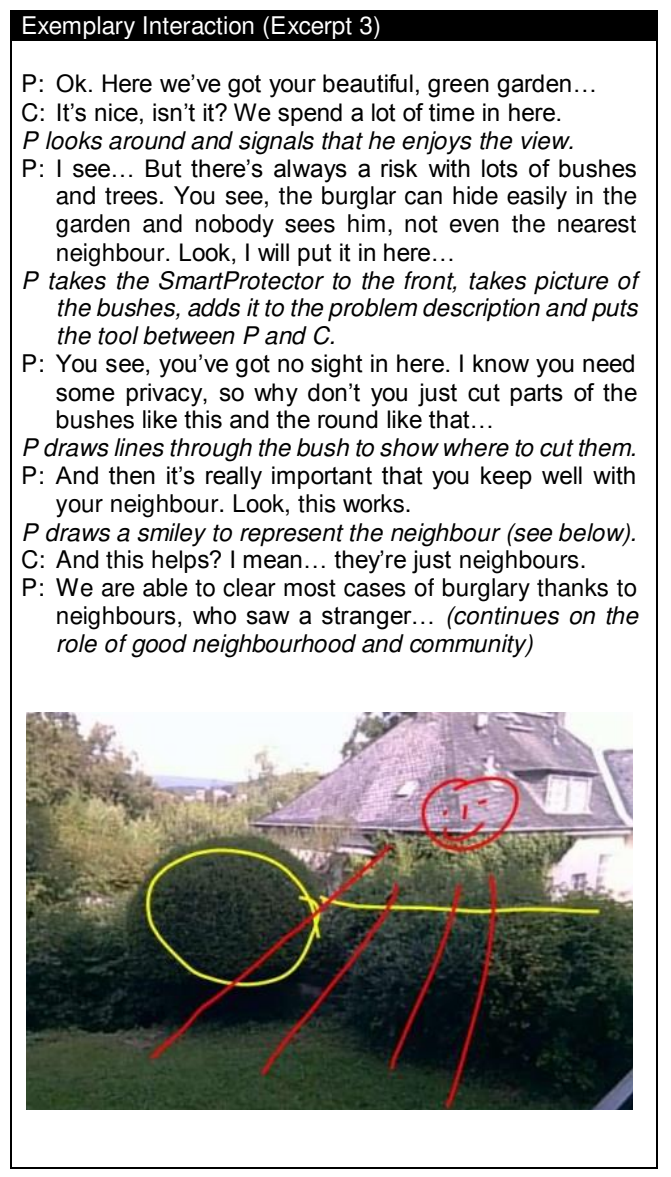

View of advisors and management: when asked for an assessment of those practices, the advisors differ in two specific points. First, some see their primary task in assessing the current state; they engage intensively in practices which clarify the reason for an issue being a problem ( $j, k$; cf. Excerpt 2$)$. Others, however, argue 
that the advisees already know or can imagine their BP security flaws and the role of the advisor is to suggest an appropriate, skilled worker-compatible solution; they focus on the solutions when approaching single security features $(h, i, l)$. Second, some advisors see media as the primary means they can use to enhance their argument for the necessity to approach a specific issue $(m, n)$ they desired more videos and pictures showing the effects of a successful burglary. An advisor even uses them to manage the impression citizens have of policeman and burglars: "Through the tablet's functionalities, I can just better explain the things to the people such that they can understand it better. And I do not have to talk that much because I can show it better with pictures or videos, for example. This is much more memorable for the people. They see their thriller on the tele and think, what they see is real. If I tell them: The police life is more boring than the thriller, they don't believe me. And this comparison holds for the tablet too. If they then see the films and characters on the tablet, or if I mark the flaws on the picture of their own window, their own door, it is more memorable for the people and they believe me more." Others, however, do not want to spread fear and choose to use multimedia primarily for explaining the solutions and proper habits, especially if people have recently been victims of a crime. However, there are also advisors who continuously try to put the problem and solution in relation to each other: with each solution they propose, they provide an explanation as to how it prevents the burglar from breaking in (cf. Excerpt 3). An advisor emphasizes the opportunity for combining her practices with SmartProtector's functionality: "I was then able to support my argument with the inserted videos, but then combined that with my conventional advice (...) For example, with the secure and unsecured window, I could then use one specimen that I've always used to present, and support this with multimedia again. Therefore, the combination was ideal." Another advisor makes clear, she leverages the SmartProtector to support her narrative concerning burglar techniques: "Finally, it complements the story, as I've done it all those years (...) When I tell the story in my advisory services and say: 'We can do something concrete such that the perpetrator doesn't get into the object so quickly', I can add: 'Let's take a look at the movie. Then you can see what such a bad lad would need to do if they wanted to get into a secured object'." While this advisor used the video to show that there are solutions, she would rather continue with her story than elaborate on the particular solution and, instead, she moved the topic to the end of her advisory session. The same advisor adds however, that how each advisor accommodates the SmartProtector may depend on that advisor's routines: "We've got a lot, many lone fighters among us. You shouldn't forget that either. They had to fight through the matter alone and compile, develop something that works for them." While the management was aware of systematic differences between advisors and about the fact that each advisor has her own default and usual routines, they were surprised by the content of the routines. For instance, it was new to the management that some advisors tend to explore the problem and only roughly 
discuss the solutions. However, they knew of the advisors who regularly specify a solution like a skilled worker would do (they called them "techies"). Still, the management did not see much advantage in probing into the mechanical details of the solutions and considered it "missing the point of advice". The management would see SmartProtector equipped with additional easy outlines and videos as part of the strategy to balance out those tendencies and to put more emphasis on convincing explanations rather than recommendations: "Some have problems to talk about the problem, I know. Look, it's so because they are often just like any policeman and think: 'These are the recommendations that we make, they're right and ours. Ineed to present the solutions and recommendations, like in a checklist'. And that's where SmartProtector can be good, because sometimes the advisee is not sure where he is and where he wants to be regarding their security (...). He needs to understand and come along, right? Sometimes you think he has understood, but he has not understood it and he does not dare asking you back".

\subsection{Security Plan}

Table 3. Practices applied to summarize the encounter.

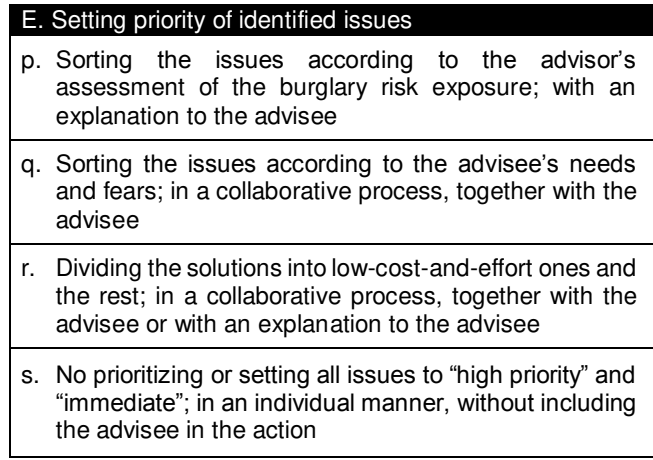

\begin{tabular}{l} 
Exemplary Interaction (Excerpt 4) \\
\hline P: So, I think, we've seen everything, haven't we? Cellar, \\
ground floor including guest toilet, first floor, garden... \\
$P$ lists the areas while distributing the issue cards across the \\
screen, $C$ and P stand next to the table, about to sit down. \\
C: It seems to me... No more questions from my side so far. \\
P: It's definitely urgent to repair the cellar door, right? But you \\
already agreed with me that they really are an issue. I will \\
put them to 'immediate' and 'high' here, on the graph... \\
C: Yeah, and the window just next to it. The grids, you know. \\
P: You're right... (searches through the issues moving them \\
on screen to different sides) There it is. OK. Then we've \\
got the balcony door. Improving them will cost money and \\
time, so maybe “middle-term" but they have a high priority \\
in my opinion - you've seen yourself, just few seconds to \\
open them if you know how... (continues with otherpoints) \\
\hline
\end{tabular}

Having identified the relevant security flaws and solution, advisors engage in summarizing the encounter. In pre-SmartProtector advisory encounters, the summaries were mostly a listing of all issues considered, which only occasionally hinted at the most urgent point, or even where to start. Since the SmartProtector clearly affords prioritization, after the roll-out the advisors established various ways for dealing with the prioritization/listing (Table 3). Two general tendencies can be observed: (1) the advisors engage in visible interaction with the SmartProtector, so that the advisee can see and understand the rationale behind the suggested order $(p$, $q, r$ ) or (2) the advisor uses SmartProtector as a private artefact, whilst giving the same urgency and priority level to all issues $(s)$. While the design rationale of the SmartProtector was to afford prioritization when considering advisee needs as well as the statistical risk (may be higher in the cellar than in the first floor), the emerging practices differ: some advisors present only their own assessment $(p)$ or they use prioritizing to highlight easy to achieve options to the advisee $(r)$. Overall, 
the practices used involve a kind of prioritizing but often disregard the advisee's position $(p, r)$ or ignore him altogether $(s)$.

View of advisors and management: when confronted with the differences concerning their prioritizing practices, advisors argue for their own personal practice when referring to their understanding of how persuasion works and what role a police officer plays in this regard. Advisors who consider advisee needs and fears or abilities during prioritization ( $q$, partially $r$ ), want the advisee to start with a solution that is most convenient to him, the advisee, and hope that he will adopt other points thereafter: "You mostly feel that they want to do something, but they do not know yet what and how - sometimes it's even difficult for me to assess, where to set the priorities. Each advisee and each house is different. (...) Do I set the priority as a consultant with police knowledge or where I would see the priority for me and my spouse? I define the prioritizing in the counselling as trying to win people over as far as I can: where do they currently have the opportunity (not just financially) of implementing something? Is it to trim the hedge? Is it to install a girder and thereby strengthen the sense of security for the first moment?" Advisors who rely on their own assessment (often supported by statistics) or see themselves as unable to provide any reasonable priority list $(p, s)$, are afraid of advisees feeling secure just because they have implemented the most urgent improvements: complete safety comes through implementation of the full "security package". Interestingly, those advisors who do not engage in prioritizing claim that the advisees are motivated enough if they pay attention to the BP service encounter, so that any further assistance in this regard is unnecessary. As an advisor puts it: "People know what they want from me. They want to have independent information from me: 'How can I secure a house as effectively as possible?' (...) I put every issue on 'immediate', and I push everything on 'as high as possible'. I also tell people very clearly: 'You know, I could tell you now that this window is more endangered than another window. But, the one perpetrator comes just over the cellar, the other offender is better over the balcony. (...) And yet another does not even try it on the ground floor, because he always works at the basement.' For me, the priorities are always at a single, constant level. That's why I postpone practically everything to 'immediate'. You cannot implement a part and think, you are more secure." Advisors, who engage in collaborative prioritizing review the issues and the proposed solutions together with the advisee, try to learn how many resources are available on the advisee's side, and try to incorporate them into their own assessment. The management members had mixed opinions about what is more important for prioritization: the advisee's situation or the advisor's assessment. Those who opted for the advisee's situation as being more important see the prioritization list primarily as a trigger for taking the next step; those who favour objective assessment (based on statistics), or the advisor's opinion, see the prioritization list as a decision support tool. Interestingly, when confronted with the statement that a very rational decision taken upon the result of an advisory session 
may be to not implement any security improvements, only one management member and no advisor accepted it as a reasonable response; all other interview partners would consider such an encounter a failure. One manager put it this way: "Our purpose is - I've said that before, so I'll say it again - actually to see that more households in our state are secured, that the rates of unsuccessful to successful burglaries are increasing. (...) For the most part, we cannot just have nice conversations with the advisees, to bring them to make risk assessment - 'Do I do something about burglary risk? Do I leave it the way it is?' That would be a total loss. A representative who works this way would be fired from his company very early if he did not bring any contracts". Many advisors share the reasoning: "Well, if someone, after the advisory session, arrives at the decision not to do anything, because 'it's just fine', then I know that in that case, I just wasted my time being there", but some directly point to a dilemma: "In a sense, it would not be a successful consultation, because I could not convince him that it is important to do what. But we also leave the decision, what is made, and the extent of the measures taken to the citizen." Apparently, even though the advisors have no explicit incentive to persuade people, and there is no way to assess their performance in this regard, the managers and the advisors understand prevention often as promotion of safety measures and appropriate behaviours to be implemented by the advisees.

\section{Discussion}

The observations illustrate a wide variety of persuasive practices. The advisors differ in the way, they introduce and incorporate SmartProtector in their encounter. However, each advisor greatly relies on the routines they re-enact over and over again in the service encounters and deviates from them only in specific cases, they can enumerate (e.g., advisee being recent victim of a burglary or crime incident). This confirms the routinized character of persuasive practices in BP. Nevertheless, whenever the advisors explain their behaviour or provide arguments for it, they refer to several basic ideas: their view of an (ideal) advisor, their picture of a standard advisee, their position in the organization. This leads to an interesting view of service encounters as collaborative achievements caught between organizational and private opinions, individual and public objectives, as well as between routine and situational behaviours. This chapter offers an interpretation of the data collected while going from the general perspective on persuasive practices, the patterns that characterize the transformation and emergence of persuasive practices and the tensions that govern those processes, to the cumulative view on the standing of persuasion in advisory services. 


\subsection{Persuasive Practices in Advisory Encounters}

The way advisors talk about their advisory practices and about what they do in practice seems to present a contradiction. On the one hand, each house, each advisee, and each door, window, etc. seem to be different and individual. On the other hand, advisors often refer repeatedly to their individual routines, specimens or the tools they present, the stories they tell, and other repeated behaviours. Interestingly, advisory sessions conducted by the same advisor are similar although they do not necessarily follow the same format, but rather rely on the same set of arguments. The advisor who presented a red screwdriver to their advisees did this each time we observed her. The same is true for a range of behaviours which, due to space limitations, could not be listed in the previous chapter. Narratives of how burglars work were popular, corresponding to the practices $j$ or $e$, or little thought experiments and anecdotes referring to the very common but unsafe behaviours of many citizens $(k)$. They form inventories of the individual advisors' emotional and rational arguments activated throughout the advisory service. A window precipitates one story and a visit to the guest toilet another one: even though each house and each advisee has their individual characteristics, the vast majority of them can be addressed with a set of one-fits-all or, rather, few-fit-many arguments. The existence of those routine arguments confirms Schegloff's (1986) view of practices as ordered, repetitive and organized sets of interactive, conversational behaviours. Persuasion in advisory encounters happens by applying reusable modules.

To a certain extent, persuasion in advisory encounters may resemble putting together stories, anecdotes, arguments and explanations; however, the activation of the routines varies and considers the external circumstances (as in Extracts 2 and 3 ) as well as interaction from the advisee (as in Extract 1). Similarly, the advisory encounters are stages of personal contact between the police officer and the citizen, where the introduction on both sides, small talk, and showing interest at the citizen is part of the work assignment as a prevention officer. From this perspective, advisory encounters are highly established collaborative achievements: the configuration of the persuasive practices and the knit that turns the encounter into a coherent experience, acknowledge the individual character of each advisee and each house. This perspective corresponds with the situated collaboration perspective (Suchman, 1987; Orlikowski, 2008). The framing of persuasive practices as routinized behaviours (and the observations that confirm this assumption) sheds new light on persuasion and makes the field particularly attractive for artefact-based interventions. Designing for persuasion in collaboration means, in light of this insight, designing for a set of persuader's narratives and arguments (e.g., affording them, complementing them with multimodal material) rather than providing artefacts or features targeting directly the persuadee. This contradicts the intuition from PT literature (Fogg, 2009; OinasKukkonen and Harjumaa, 2009; Oinas-Kukkonen, 2010), which sees the persuadee 
as the primary design's addressee. PT designed for a co-located collaborative situation, such as the BP encounter, only can have an impact if it can address the persuader's behaviour.

The notion of persuasive practices illustrated in the study adds to the insights provided in persuastion and persuasive technology literature. First and foremost, previous literature defined persuasion in terms of a persuasive intent on persuader's side (Chaiken, 1980; Chaiken, 1987; Fogg, 2009; Stibe and Oinas-Kukkonen, 2014). This article shows that persuasion may require a practice-based model: persuasive practices occur in the burglary prevention encounters whether or not the advisors consciously intend to persuade or convince the advisee. Persuasive technology studies often claim a persuasive intent and, to a certain extent, follow the way of technological determinism to argue for the persuasive effect (Fritz et al., 2014; Stibe, 2015) - even in situation involving interaction between humans, like in university setting (Stibe and Oinas-Kukkonen, 2014). This article, based on the provided results, points in a different direction: it is the embedding of technology in a context that makes it persuasive. Second, it illustrates that not the content, but also the form have a central impact on the persuasion effectiveness. Advisors (and, also, advisees) talk about "the videos", "the questions" and "the graphics" rather than referring to the essence of those elements. This is consistent with an already published analysis (Comes and Schwabe, 2016b), but the current study suggests that the form is also essential for the acceptance of specific affordances by the persuaders. In particular, the videos and illustrations get well integrated in the advisory practices, while suggested protection needs questions and priorities get refused. We offer the following explanation: while videos and solution illustrations complement the advisory practices, which have mostly conversational or embodied character, the quite concrete formulation of needs and the direct message of the priority diagram may directly counter the advisor's statements. Consequently, persuasive content in face-to-face persuasion will be appropriated easily if provided in an adequate form. Overall, the current article suggests that framing persuasion as practice offers valuable insights about how to support it with technology.

The identified character of persuasive practices provides potential for fascinating design challenges. Equipping the advisors with specific narratives or thought experiments may be an effective way of introducing new topics into their routine. For instance, SmartProtector's prioritization affordance was not completely used as intended, but many advisors started discussing the topic in their advisory encounters; even the advisor cited, who did not prioritize issues, established an argument she used in many advisory encounters and referred to in the interview. Similarly, the initiation of the discussion on advisee needs was introduced in the training before the roll-out and many advisors used it like another narrative, while preparing space for interaction with the advisee. However, providing the "modules" is not the only way to intervene: the same is true for extending the situation by providing space to "dock" those modules. Using the 
SmartProtector as an excuse for saying that something may not be the most elegant option gave the advisors a motive for activating the practice as they activate their narratives when seeing a window, door or a phone. Some advisors establish such dock sites themselves, whenever they present a specimen or draw a house. In other words, transforming persuasive practice is not about teaching the advisors about persuasion, rather more about providing them with scripts to be reused frequently, and about providing them with events that launch the script.

\subsection{Patterns for appropriation of persuasive technology in advisory services: Denying, Censoring, Executing and Accommodating}

We observed a set of advisors' approaches towards SmartProtector: (1) denying: advisors systematically ignore a specific use, while arguing against it by emphasizing understanding of their own role or the stereotype of the advisee; (2) censoring: advisors occasionally ignore a specific usage or reject a functionality, while providing an established explanation for their behaviour; (3) executing: advisors systematically enact the intended persuasive practice and assess its effectiveness; (4) accommodating: advisors systematically conciliate their preexisting routines with the SmartProtector functionalities (as intended by the design or in a new, creative way) Whether the advisors censor, deny, execute or accommodate them goes far beyond the circumstances and setting of a single situation. This is far more finely-tuned and fluid than the static, holistic views of technology acceptance and utility (Fidock and Carroll, 2010). The behaviour patterns presented here also differ from appropriation types or appropriation moves which can be negotiated between users, be it in a co-located (DeSanctis and Gallupe, 1987) or distributed scenario (Richter and Riemer, 2009). Driven by the need to maintain a good impression on the advisee, the advisor changes her routines and develops new practices in an implicit way. The behaviour patterns become explicit through later reflection, like the tensions that drive the advisors towards one or another behaviour.

Advisors identify different reasons for leaving the established way and deviating from traditional practice and, even, from personal routines. An example is the adhoc censoring of behaviours that would otherwise form a stable part of one's personal conduct. The most prominent case of censoring among BP advisors was the case where advisors skipped the most emotional parts of their narrative or did not show emotionally loaded multimedia when they encountered a highly emotional or traumatized person; be it a recent victim of burglary or somebody expressing intense fears. In those cases, the advisors reduce the amount of emotional content concerning security flaw identification (see 5.2) or they censor questions inappropriate for a traumatized person (see 5.1). The advisors themselves point to those cases as the ones which require very sensitive conduct and adaptation to the advisees' pace and emotions (see 5.2), thus confirming that the advisory 
encounters are strongly contextualized and situated (Fischer et al., 2014; Fischer et al., 2017). This also points to the importance of maintaining the fear of crime at an appropriate level as a prerequisite for advisee's action (Gabriel and Greve, 2003; Bernasco, 2014). This situated censorship is different from denial of the emotional content in the advice-giving.

Some advisors systematically omit emotional content (see 5.2), others systematically omit specifying a concrete suggestion (see 5.3). The argument those advisors give differs from the one for censoring. They deny formulating a very concrete suggestion and an action plan (be it created together with the advisee or by the advisor only) because they appreciate the negative consequences if such a plan were to be implemented but the burglar still found a way to break in (no measure gives "complete" security and each material, even bullet-proof glass, may break under enough force). Consequently, they deny the practice based on a general assumption about their responsibility. In such situations, the advisors have prepared a set of answers they employ if an advisee asks, e.g., "We are a public agency and cannot give any recommendation about a particular company - neither a positive nor a negative one, but "so-and-so" provides a list of companies certified by an independent institute". Similarly, advisors deny talking about or asking advisees about their emotions because of their subjective character or because they assume that all advisees share a common emotion they can build upon; namely, moderate fear of burglary crime (see 5.1). Advisors who deny specific practices, even when confronted with their colleagues who employed those practices denied even before SmartProtector's roll out, use categorical arguments; they refer to the police as a public institution, to the police officer as its representative, to the default situation and a default advisee. This supports the notion of persuasive practices as a routine sourcing at social and organizational discourses (Schegloff, 1986; Scollon, 2001), rather than situated behaviour.

However, in many cases, the advisors simply follow the tool's intended practices. In specific cases, this is even expressed in the discussion with the advisee (see 5.1) because the tool/management permit something, they simply carry out this activity. This was often an explanation for collecting the advisee's data or taking a picture of the front of the house to be included in the documentation; those activities essentially do not contradict the basic assumptions advisors have about their work, and are often used to excuse the tool and execute an activity (see 5.1). Some advisors repeat the excuse and execute sequence whenever they engage in a practice for the first time (e.g., showing a video). We assume, the excuses signalize advisor's sensitivity to scripts and to the fact, that the advisees may expect a specific script (independent of whether the advisees do so or not). Again, this behaviour positions persuasive practices at the centre of social structures and discourses (Scollon, 2001) and signalizes that the upcoming behaviour exceeds the conversational and interactional routine, an advisee may expect (Schegloff, 1986). 
Integration occurs when the advisor accommodates her own routines and the action offerings of the tool, so that they fit together. Excerpt 3 in 5.2 illustrates such situation: an advisor, who previously relied on narratives to explain the necessity to cut down trees and bushes in the garden, makes extensive use of the photodrawing functionality (intended to afford collaborative drawing for identification of strong and weak points concerning security flaws) to make a suggestion of how the garden should look to reduce burglary risk. Apart from gesticulation, the narrative now receives another supporting means of communication: the picture. Similarly, the advisors were able to integrate the videos for motivating the advisees in their narratives, but only a few of them reported using the video functionalities for explaining rather than motivating solutions because the narratives and routines did not leave space for such illustrations; instead, pictures, gesticulation and verbal explanations were used. This shows that different appropriation forms can co-exist within a single interaction and form a routine (Schegloff, 1986). Importantly, the advisees' behaviour did not signalize any negative surprise.

\subsection{Dialectics of persuasion in advisory encounters}

The advisors - if confronted with a specific situation in the discussion with the observer - tend to explain their behaviour with their views regarding the work as an advisor, the relationship with the organization they represent, the stereotypes of the advisee, and their preferences on how they like to interact with people (being extravert, provocative, etc.). Thereby they point to opposing forces, i.e., dialectic tensions. We argue that similar tensions will occur in other service encounters where persuasion may in fact positively contribute to the quality of beneficent advisory encounters, for instance in doctor-patient encounters (Jungermann, 1999; Yaniv, 2004b; Swindell et al., 2010). Importantly, the identification of those tensions and divergent practices was possible due to the organizational roll-out of the SmartProtector. Even though the system was extensively tested and developed over several years, also in relation with identified practices, the appropriation in daily practice brought tensions to the surface, which were otherwise hidden.

\subsubsection{Motivating vs. enabling practices}

The occurrence of such practices as $d$ ("accepting needs and fears without discussion"), as opposed to $a, b$, or $c$, as well as $s$ ("no prioritizing"), as opposed to $p, q$, and $r$, points to an essential tension that characterizes the advisor's work: the tension between motivating the advisee and enabling the advisee. Some advisors systematically discount the role of the advisee's emotions and deny the action offerings in this connection. They do not engage in a discussion of the advisees' needs or fears and refer to objective rather than subjective facts about a security flaw, thus discounting essential affordances of SmartProtector to motivate the 
advisee by adding an emotional dimension to a personalized problem and solution description. This happens even though the advisors are aware of the role of emotions as a motivating force. Whereas censoring some activities has an established explanation, advisors who systematically treat advisee's emotions and fears as insignificant or irrelevant to their task tend to refer to a stereotype of a police officer as somebody acting in the public interest, someone who needs to consider data and who should remain down to earth. Furthermore, by doing so they represent a picture of an advisee who needs facts to make the proper decision. Such advisors overestimate the role of rational decision-making. This is contradictory to the available models of human behaviour change (Chaiken, 1980; Fogg, 2009; Oinas-Kukkonen and Harjumaa, 2009; Kahneman, 2011; Petty, 2013). However, some advisors choose another behaviour - they include basic information on the available solutions but focus on bringing the advisee to do "something", i.e., they engage more in the narratives of known or recent burglary cases. They shape a police officer as somebody with access to exclusive stories that should leave a longlasting impression on the advisee. By moving the responsibility for any technical decision to the advisee and skilled workers, they seem to underestimate the ability aspect of persuasion. In both cases, we observe that the advisors ignore one of the persuasive dimensions and overemphasize the other one.

This may be detrimental to the persuasive effect. Current persuasion models all agree that emotions (motivation) and cognition (ability) are necessary for a sustainable response to a persuasion effort (Chaiken, 1980; Chaiken, 1987). However, none of the models makes clear how to balance between emotions and cognition, or, in the context of PT, motivation and enablement (Fogg, 2009; OinasKukkonen and Harjumaa, 2009; Stibe and Oinas-Kukkonen, 2014). Advisors who are successful at balancing between motivating and enabling examine their stereotype of the advisee at the beginning of the encounter - they invest time in understanding whether a rational or an emotional need underlies the advisee's request for an advisory session. Therefore, they employ an open question or a set of open questions and let the advisee explain their situation; they accommodate the list of potential needs to assess the advisee even further and adapt their main message to fit the corrected vision of the conversation partner. Later, they alternate between emotionally-loaded and cognitively-loaded messages. We claim, that this alternation between enabling (rational) and motivating (emotional) messages protects the cognitive and emotional systems of the advisee from overload and keeps both systems awake and receptive to the messages (Kahneman, 2011).

\subsection{2 “As-is" vs. "to-be" practices}

The problem-solving literature sees the process of moving between the "as-is" towards the "to-be" state as the solving procedure (Simon, 1978) - persuasion research supports this view and suggests that one of PT's tasks is to support simulation by illustrating the opposite dimensions (Oinas-Kukkonen and 
Harjumaa, 2009). Therefore, SmartProtector offers ways to document or visualize both dimensions. However, we observed that some advisors put more emphasis on "to-be" rather than "as-is". In particular, they "indicate that a particular possible security improvement is missing" and "provide general assessment of a feature as "insufficient" (practices $h$ and $i$ ) rather than "clarifying how a burglar might use the current weak point to break in" and "clarifying why present security solutions are incompatible with the advisee's needs and habits" ( $j$ and $k$ ). Even though SmartProtector offers extensive ways to describe a problem in terms of "as-is" (cf. Figure 2 right), many advisors define the problem in terms of a missing solution ("this window is insecure because it lacks a grid") and so they use, e.g., the drawing functionality to draw a grid on the window. Consequently, some advisees receive a sparse and general description of the "as-is" state but receive an individualized recommendation; a "to-be" state without understanding the rationale behind it. However, as some advisors claim using SmartProtector made clear to them, that specifying a problem needs more attention and so they changed their routine: they invest more effort in explaining why a problem is a problem. On the opposite side, there are also advisors who deny discussing solutions in detail. They routinely use a narrative that explains what safety issue the burglar is looking for, why, and where the advisee's house has those weaknesses. While the narrative is right at the heart of this practice, the "to-be" dimensions plays a secondary role. We claim that the rhetoric structure of an argument or a narrative hamper the introduction of solutions; those advisors make extensive use of, for instance, the problem videos that support their story, but move explanation of the solution to a later time, a brochure, or even to the skilled worker. Interestingly, when confronted with those observations, many advisors consider the idea of "as-is" and "to-be" very natural and would think, their practices actually embrace both - they were surprised when pointed to the contrary instance behaviours. For the advisee, who cannot assess the "as-is", recommendations from the advisor become atomic and fragmented. Without perspective for solution, the listing of problems may overwhelm.

We claim, the imbalance between "as-is" and "to-be" modes results from the expertise, advisors have. Advisors can easily identify the right solution for a situation without much cognitive effort, be it through back-tracking or through inducing the right solution based on previously seen cases in the technical training (Kahneman, 2011) - a typical behaviours for domain experts. The advisees neither have access to the collection of similar cases nor are they able to back-track if they do not understand the "as-is" state. Consequently, communication about a problem and solution in an advisory encounter needs to be oriented towards making this connection between the problem and the solution explicit and comprehensible. However, the evolution of advisory services from recommending (Jungermann, 1999; Bonaccio and Dalal, 2006) towards joint problem solving (Giesbrecht et al., 2016; Dolata and Schwabe, 2017b) requires that both participants establish a common understanding. Advisors, who are best at dealing with the tension between 
"as-is" and "to-be" when discussing security issues start with a brief problem definition by explaining the burglar's thinking and approach to the advisee. Then they propose a solution or partial solution (e.g., locking handle), and present how a locking handle hinders a break-in. The SmartProtector offers the simplistic metaphor of an issue card with a problem and solution area to afford alternating between the "as-is" and "to-be" dimensions.

\subsubsection{Persuasion as decision support vs. persuasion as selling}

As has already been shown, some advisors omit essential steps in the proposed persuasive process while leaving out discussion of the advisee's needs ( $b$ and $g$ ) or by discounting the role of prioritizing $(s)$. Sometimes, they even suggest several alternative solutions without making recommendations. While, as mentioned, this can lead to an imbalance between motivation and ability on the advisee's side, it has another implication for the advisory process: it ignores the interactive, personalized and subjective service dimensions. The discussions about an advisors' personal definition of their job highlights what the conflict is de facto about: the advisors link activities using objective data with supporting decision and the activities which have an openly motivating character with selling. Clearly, the advisors do not accept the picture of selling security; through emphasizing their lack of involvement, they stress their understanding of their role as being providers of decision support. However, when confronted with specific questions, they admit that a successful encounter will lead the advisee to improve their security (even if monetary or rational reasoning is against it: losses due to a burglary incident may be far lower than the investment needed to improve the security). Consequently, they feel torn by the need to make the advisee improve their security and the feeling that they should stay objective and uninvolved.

This tension has a classical dialectic character because the opposing forces originate in the organizational embedment of the advisory encounter (Ven and Poole, 1995). The advisors know the expectations of the different sides: the management, society, and the government want to see the number of successful burglary incidents fall; at the same time, the police are expected to provide independent, open, and honest advice. This conflict is typical for non-commercial encounters: whereas in commercial encounters, clients expect the advisor to follow a hidden agenda, a non-commercial encounter should be free of advisors' private interests (Swindell et al., 2010). In the terminology of PT, the typical picture of the commercial selling situation implies the endogenous intent (Fogg, 2009; OinasKukkonen and Harjumaa, 2009) - the persuader is different from the persuadee and follows own interests. In many situations, the persuasive intent may be autogenous, i.e., where the persuadee and persuader are one and the same person who persuades herself to an attitude or behaviour change (e.g., eating less). If the persuasive intent comes from outside the persuader or the persuadee, it is exogenous (Fogg, 2009). According to the collected data, the non-commercial encounters, like the BP case, 
have a mixed character: the primary intent has social or organizational origin (exogenous), but the advisors' statements make clear, that they identify themselves with that, wanting to persuade the advisee (endogenous) and the advisees mostly seek motivation and enablement in this domain (autogenous). This makes the BP case particularly challenging for technology design.

Compared to the most typical PT application scenario (a single user employing an app to do more sports, lose weight, quit smoking, etc.), PT for non-commercial service encounters cannot assume the typical motivation schema, which assumes the initial motivation to be high and takes care of keeping it high, while enabling the user more and more (Oinas-Kukkonen and Harjumaa, 2009; Fritz et al., 2014). It cannot also make the assumptions of persuasive technology developed for collaboration between individuals involving monetary incentives where the persuader has immediate interest in changing the attitude of the opposite side (Yang and Kraut, 2017). Similarly, emphasizing common interests, common background or personal relation might excellently support teams of peers (Yang and Kraut, 2017), but the considered advisory encounters emerged particularly for bringing together people with different backgrounds and interests (e.g., policemen and property owners). Compared with advice giving support technologies (Heinrich et al., 2014; Heyman and Artman, 2015; Giesbrecht et al., 2016), the SmartProtector adds the emotional dimension of long-term motivation. Previous research focused primarily on enabling the advisee or the advisor by preparing, visualizing or providing specific information (Nussbaumer et al., 2012; Giesbrecht et al., 2016; Fischer et al., 2017), and addressed the emotional issues like rapport building (Heinrich et al., 2014) or hedonic qualities of the experience (Novak and Schmidt, 2009) only to serve the immediate goals of the encounter (involvement in rational problem solving or recommendation-oriented advice giving) and not to establish a lasting effect.

\subsubsection{Stereotype of the motivated advisee vs. the materialist}

Whereas the conflicts above are oriented primarily at understanding of the advisor's own role, and how they orient themselves towards the various expectations, there are also conflicts about the advisors' image of the advisee. However, there is more to it than that. We claim that the way humans behave in collaborative situations depends predominantly on their assumptions about the collaboration partners. Conversation-analytical and communication studies about institutional talk demonstrate well the adaptation in dialogue which is a phenomenon that follows from adjusting the assumptions about the other side and stresses the fact that many behaviours are only meaningful if one considers the institutional identities of the collaborators, which normally remain stable (Drew and Heritage, 1992). Stable, but definitely not uniform: advisors explain their behaviour by referring to different, even contradictory mental images of an advisee. Some assume the advisee to be motivated to improve their security from the very beginning, just because they take 
part in a BP advisory session; those advisors are likely to systematically deny motivating practices but emphasize their specific vision of a solution. Others presuppose that an advisee lacks motivation or does not attach the highest priority to the burglary prevention or he may be reluctant to adopt any change; those advisors have a tendency to motivate the advisee more and make the BP attractive to them. Consequently, they use the system in a way that fits their advisee stereotype. The less time the advisor invests in correcting this stereotype, the larger the risk of falling back into the old routines. If the routines do not fit the advisee's biases and presuppositions, the effectiveness of the persuasive practices will remain low.

However, technology is not just a passive tool in this regard. A system envisioned to support a specific collaborative scenario necessarily implies an image of the collaborators: in our case, the advisor and the advisee. Part of the image of the advisor is his image of the advisee and vice versa. If there is an essential inconsistency in how the advisor sees the advisee and the image of the advisee implied in the system's design, the likelihood of denying or fixing the intended practices rises. Therefore, it is essential to consider the implied collaborator as a structure to be analysed in appropriation studies.

\section{Limitations and conclusion}

Whereas the extensive qualitative apparatus proves helpful at identifying practices as well as the dialectic tensions that shape them, those insights do not come without limitations. First, the reliability of coding could be further improved by the participation of an additional coder and the computation of the interrater agreement. Second, video recording of advisory sessions would enable a more precise analysis of specific practices, especially in those cases where formulation of concrete statements is essential (cf. practices $a$ to $c$ ). Third, the generalization and external validity of the constructs presented in the current manuscript would benefit from triangulation with another, related case of non-commercial encounters, e.g., advisory encounters on smart or ecological living.

With those limitations, this study makes contributions beyond the context of burglary prevention advisory services. First, it lists and characterizes several persuasive practices occurring in advisory services; they are often routinized narratives or performances rather than improvisations, but their activation is based on the situation. This may resemble other expert-layperson settings like, e.g., student counselling in academia, where the teacher uses a set of standard narratives and sayings to persuade the student to follow a proposed path. Sports trainers rallying their team before a match are a typical example, showing that motivating somebody has a routinized character; similarly, BP advisors also have motivating slogans including the "Don't be afraid, but..." phrases or specimens, such as the screwdriver they always carry. This adds to the knowledge on interpersonal persuasion which forms a basis for PT but is becoming increasingly important in 
beneficent advisory services too. Second, the study explains the patterns involved in the appropriation of a persuasive system in a collaborative situation and the conflicts which drive how the advisors use the system. The advisors seem to deny specific practices which contradict their own understanding and role and their stereotype of the citizen; for instance, they act based on a vision of an objective, an uninvolved police officer or a citizen-friendly advisor. Thereby, they embody and broadcast a vision of public service which they adhere to and, accordingly, they do or do not take on the ideas offered by the technology. This adds to the understanding of using technology in a whole class of frontline situations, whenever citizens encounter a representative of the state. Similarly, this study exemplifies how dialectic perspective can be leveraged to understand the rationale behind specific appropriation patterns. Third, the study presents the design of a system which combines state-of-the-art knowledge of mobile support for advisory encounters with the rationales of PT, crime prevention and joint problem-solving. The analysis of previous practices, not only in terms of chronological happenings but also in relation to theoretical accounts, helped with understanding what actually happens in the interaction and what transformation is necessary. This lead to design solutions such as affording a problem-solving approach via problem and solution areas combined in an issue card, along with provision of striking videos for motivation and schematic information for enablement and empowerment. The proposed design can be adapted to similar areas including energy-saving encounters, prevention of crime and sexual assault in an office environment, doctor-patient settings, etc., thus being of high relevance to the engineers and designers involved in digitalization of service encounters. Managers and designers also benefit from better understanding of the various factors that influence the appropriation of software among frontline employees. Additionally, CSCW discourse gains extended insight into a specific class of collaboration scenario advisory encounters. The focus and the results extend the range of previously considered topics (conversation quality, data work, impression management, relationship building) by focusing on persuasion as a part of advice-giving. Since the advisory encounters form a complex form of collaboration (impacted by the organizational embedment, structures of incentives, institutional character of talk and, recently, growing pressure for change and digitalization), we call for further research in this area: for the identification and description of new interesting phenomena, as well as for design and engineering efforts in this area.

\section{Acknowledgments}

We send our best thanks to all police officers, who generously supported this study. Special gratitude to those who agreed to observations, shared their insights and observations with us, spent hours on discussing the issues, or helped us with formal issues. Roger, Hugo, Christoph, Rolf, Markus, Max, Michael P., Thomas, Stefan, 
Frank, Michael C., Sven, and Reinhard - without your assistance and openness this study would not have been possible. We thank Dr. Tino Comes for his hard work on SmartProtector design and development, as well as for his overall supportive attitude. Finally, our best thanks to the involved police departments for supporting the project financially and mentally.

\section{References}

Anderson, Catherine L.; and Ritu Agarwal (2010). Practicing Safe Computing: A Multimedia Empirical Examination of Home Computer User Security Behavioral Intentions. Management Information Systems Quarterly, vol. 34, no. 3, pp. 613-643.

Barberet, Rosemary; and Bonnie S. Fisher (2009). Can security beget insecurity? Security and crime prevention awareness and fear of burglary among university students in the East Midlands. Security Journal, vol. 22, no. 1, pp. 3-23.

Bernasco, Wim (2014). Residential Burglary. In Gerben Bruinsma and David Weisburd (eds.): Encyclopedia of Criminology and Criminal Justice, pp. 4381-4391. Springer New York.

Bonaccio, Silvia; and Reeshad S. Dalal (2006). Advice taking and decisionmaking: An integrative literature review, and implications for the organizational sciences. Organizational Behavior and Human Decision Processes, vol. 101, no. 2, pp. 127-151.

Bouwman, Machtelt G.; Quirine GA Teunissen; Frits A. Wijburg; and Gabor E. Linthorst (2010). 'Doctor Google'ending the diagnostic odyssey in lysosomal storage disorders: parents using internet search engines as an efficient diagnostic strategy in rare diseases. Archives of Disease in Childhood, vol. 95, no. 8, pp. 642-644.

Carlo, Jessica; Kalle Lyytinen; and Jr Richard Boland (2012). Dialectics of Collective Minding: Contradictory Appropriations of Information Technology in a High-Risk Project. Management Information Systems Quarterly, vol. 36, no. 4, pp. 1081-1108.

Chaiken, Shelly (1980). Heuristic versus systematic information processing and the use of source versus message cues in persuasion. Journal of Personality and Social Psychology, vol. 39, no. 5, pp. 752-766.

Chaiken, Shelly (1987). The heuristic model of persuasion. In Social influence: the Ontario symposium, vol. 5, pp. 3-39.

Cho, Sunyoung; and Lars Mathiassen (2007). The role of industry infrastructure in telehealth innovations: a multi-level analysis of a telestroke program. European Journal of Information Systems, vol. 16, no. 6, pp. 738-750.

Cialdini, Robert B. (2007). Influence: the psychology of persuasion. Rev. ed. New York, NY: Collins.

Comes, Tino; and Gerhard Schwabe (2016a). From Fuzzy Exploration to Transparent Advice: Insights into Mobile Advisory Services. In T. X. Bui R. H. Sprague (eds): HICSS-49. Proceedings of 49th Hawaii International 
Conference on System Sciences, Kauai, Hawaii, USA, 5 January - 8

January. Los Alamitos, USA: IEEE, pp. 1256-1265.

Comes, Tino; and Gerhard Schwabe (2016b). How to diminish advice discounting with mobile multimedia interventions. In ECIS 2016. Proceedings of European Conference on Information Systems, Istanbul, Turkey, 12 June 15 June. Atlanta, USA: AIS.

Davis, Robert C.; and Barbara Smith (1994). Teaching Victims Crime Prevention Skills: Can Individuals Lower their Risk of Crime? Criminal Justice Review, vol. 19, no. 1, pp. 56-68.

DeSanctis, Gerardine; and R. Brent Gallupe (1987). A Foundation for the Study of Group Decision Support Systems. Management Science, vol. 33, no. 5, pp. 589-609.

DeSanctis, Gerardine; and Marshall Scott Poole (1994). Capturing the complexity in advanced technology use: Adaptive structuration theory. Organization science, vol. 5, no. 2, pp. 121-147.

Dolata, Mateusz; Tino Comes; Birgit Schenk; and Gerhard Schwabe (2016). Persuasive Practices: Learning from Home Security Advisory Services. In PERSUASIVE 2016. Proceedings of International Conference on Persuasive Technology, Salzburg, Austria, 5 April - 7 April 2016. Cham, Switzerland: Springer International Publishing, pp. 176-188.

Dolata, Mateusz; and Gerhard Schwabe (2017a). Involvement Practices in Persuasive Service Encounter: The Case of Home Security Advice. In I. Ramos, V. Tuunainen, H. Krcmar (eds): ECIS 2017. Proceedings of the 25th European Conference on Information Systems, Guimaraes, Portugal, 5 June - 10 June 2017. Atlanta, USA: AIS, pp. 1869-1884.

Dolata, Mateusz; and Gerhard Schwabe (2017b). Tuning in to More Interactivity - Learning from IT Support for Advisory Service Encounters. $i$-com: Journal of Interactive Media, vol. 16, no. 1, pp. 23-33.

Dolata, Mateusz; and Gerhard Schwabe (2017c). Paper Practices in Institutional Talk: How Financial Advisors Impress their Clients. Computer Supported Cooperative Work (CSCW), vol. 26, no. 4-6, pp. 769-805.

Dourish, Paul (2001). Where the action is: the foundations of embodied interaction. Cambridge, USA: MIT Press.

Dourish, Paul (2003). The appropriation of interactive technologies: Some lessons from placeless documents. Computer Supported Cooperative Work (CSCW), vol. 12, no. 4, pp. 465-490.

Dourish, Paul (2013). Epilogue: Where the action was, wasn't, should have been, and might yet be. ACM Transactions on Computer-Human Interaction, vol. 20, no. 1, pp. 1-4.

Drew, Paul; and John Heritage (1992). Talk at work: interaction in institutional settings. Cambridge; New York: Cambridge University Press.

Erete, Sheena Lewis (2013). Protecting the home: exploring the roles of technology and citizen activism from a burglar's perspective. In W. E. Mackay, S. Brewster, S. Bodker (eds): CHI'13. Proceedings of the SIGCHI Conference on Human Factors in Computing Systems, Paris, France, 27 April - 2 May 2013. New York, USA: ACM, pp. 2507-2516. 
Escarrabill, J.; T. Martí; and E. Torrente (2011). Good morning, doctor Google. Revista portuguesa de pneumologia, vol. 17, no. 4, pp. 177-181.

Fidock, Justin; and Jennie Carroll (2010). Theorising about the Life Cycle of IT Use: An appropriation perspective. Information Systems Foundations, pp. 79-112. Canberra, Australia: ANU Press.

Fischer, Joel E.; Enrico Costanza; Sarvapali D. Ramchurn; James Colley; and Tom Rodden (2014). Energy advisors at work: charity work practices to support people in fuel poverty. In UbiComp'14. Proceedings of the 2014 ACM International Joint Conference on Pervasive and Ubiquitous Computing, Seattle, USA, 13 September - 17 September 2014. New York, USA: ACM Press, pp. 447-458.

Fischer, Joel E.; Andy Crabtree; James A. Colley; Tom Rodden; and Enrico Costanza (2017). Data work: how energy advisors and clients make IoT data accountable. Computer Supported Cooperative Work (CSCW), vol. 26, no. 4-6, pp. 1-30.

Fogg, Brian J. (2009). A behavior model for persuasive design. In S. Chatterjee, P. Dev (eds): PERSUASIVE 2009. Proceedings of the 4th International Conference on Persuasive Technology, Claremont, USA, 26 April - 29 April 2009. New York, USA: ACM Press.

Fritz, Thomas; Elaine M. Huang; Gail C. Murphy; and Thomas Zimmermann (2014). Persuasive Technology in the Real World: A Study of Long-term Use of Activity Sensing Devices for Fitness. M. Jones, P. Palanque, A. Schmidt, T. Grossman (eds): CHI'14. Proceedings of the ACM Conference on Human Factors in Computing Systems, Toronto, Canada, 26 April - 01 Mai 2014. New York, USA: ACM Press, pp. 487-496.

Gabriel, Ute; and Werner Greve (2003). The Psychology of Fear of Crime. Conceptual and Methodological Perspectives. The British Journal of Criminology, vol. 43, no. 3, pp. 600-614.

Garfinkel, H (1967). Studies in Ethnomethodology. Prentice-Hall.

Giesbrecht, Tobias; Tino Comes; and Gerhard Schwabe (2015). Back in Sight, Back in Mind: Picture-Centric Support for Mobile Counseling Sessions. In D. Cosley, A. Forte, L. Ciolfi, D. McDonald (eds): CSCW'15. Proceedings of the Conference on Computer Supported Cooperative Work and Social Computing, Vancouver, Canada, 14 March - 18 March 2015. New York, USA: ACM Press, pp. 486-495.

Giesbrecht, Tobias; Hans Jochen Scholl; and Gerhard Schwabe (2016). Smart advisors in the front office: Designing employee-empowering and citizencentric services. Government Information Quarterly, vol. 33, no. 4, pp. 669-684.

Heinrich, Peter; Mehmet Kilic; Felix-Robinson Aschoff; and Gerhard Schwabe (2014). Enabling relationship building in tabletop-supported advisory settings. In S. Fussell, W. Lutters, M. Ringel Morris, M. Reddy (eds): CSCW'14. Proceedings of the 17th Conference on Computer Supported Cooperative Work and Social Computing, Baltimore, USA, 15 February 19 February 2014. New York, USA: ACM Press, pp. 171-183. 
Heyman, Susanna; and Henrik Artman (2015). Computer Support for Financial Advisors and Their Clients: Co-creating an Investment Plan. In D. Cosley, A. Forte, L. Ciolfi, D. McDonald (eds): CSCW'15. Proceedings of the 18th Conference on Computer Supported Cooperative Work and Social Computing, Vancouver, Canada, 14 March - 18 March 2015. New York, USA: ACM Press, pp. 1313-1323.

Jungermann, Helmut (1999). Advice giving and taking. In HICSS-32. Proceedings of the 32nd Hawaii International Conference on System Sciences, Maui, Hawaii, USA, 5 January - 8 January 1999. New Jersey, USA: IEEE, pp. 1-11.

Kahneman, Daniel (2011). Thinking, Fast and Slow. New York, USA: Farrar, Straus and Giroux.

Kilic, Mehmet; Mateusz Dolata; and Gerhard Schwabe (2017). Why do you ask all those questions? Supporting client profiling in financial service encounters. In T. X. Bui R. H. Sprague (eds): HICSS-50. Proceedings of the Hawaii International Conference on System Sciences, Waikoloa Beach, HI, USA, 4 January - 7 January 2017. New Jersey, USA: IEEE, pp. 4695-4704.

Kuutti, Kari; and Liam J. Bannon (2014). The turn to practice in HCI: towards a research agenda. In M. Jones, P. Palanque, A. Schmidt, T. Grossman (eds): CHI'14. Proceedings of the ACM Conference on Human Factors in Computing Systems, Toronto, Canada, 26 April - 01 Mai 2014. New York, USA: ACM Press, pp. 3543-3552.

Leune, A. S.; and J. Nizard (2012). Doctor Google: use of Internet during pregnancy in France in 2009. Journal de gynecologie, obstetrique et biologie de la reproduction, vol. 41, no. 3, pp. 243-254.

Madero-Hernandez, Arelys; Bonnie S. Fisher; and Pamela Wilcox (2016). Exploring the overlap between individualistic and collective crime prevention. Crime Prevention and Community Safety, vol. 18, no. 4, pp. 245-265.

Myers, Michael D. (1995). Dialectical hermeneutics: a theoretical framework for the implementation of information systems. Information Systems Journal, vol. 5, no. 1, pp. 51-70.

Nicolini, Davide (2012). Practice Theory, Work, and Organization: An Introduction. Oxford: Oxford UP.

Novak, Jasminko (2009). Mine, Yours... Ours? Designing for principal-agent collaboration in interactive value creation. In WI 2009. Proceedings der 9. Internationalen Tagung Wirtschaftsinformatik, Vienna, Austria, 25 February - 27 February 2009. Atlanta: AIS.

Novak, Jasminko; and Susanne Schmidt (2009). When Joy Matters: The Importance of Hedonic Stimulation in Collocated Collaboration with Large-Displays. In T. Gross, J. Gulliksen, P. Kotzé, L. Oestreicher, P. Palanque, R.O. Prates, M. Winckler (eds): INTERACT 2009. Proceedings of the 13th International Conference on the Human-Computer Interaction, Uppsala, Sweden, 24 August - 28 August 2009. Heidelberg, Berlin, Germany: Springer-Verlag Berlin Heidelberg. 
Nussbaumer, Philipp; Inu Matter; and Gerhard Schwabe (2012). "Enforced" vs. "Casual" Transparency - Findings from IT-Supported Financial Advisory Encounters. ACM Transactions on Management Information Systems, vol. 3, no. 2, pp. 11:1-11:19.

Oinas-Kukkonen, Harri (2010). Behavior change support systems: A research model and agenda. In T. Ploug, P. Hasle, H. Oinas-Kukkonen (eds): PERSUASIVE 2010. Proceedings of the 5th International Conference on Persuasive Technology, Copenhagen, Denmark, 7 June - 10 June 2010. Heidelberg, Berlin, Germany: Springer-Verlag Berlin Heidelberg, pp. 4 14.

Oinas-Kukkonen, Harri; and Marja Harjumaa (2009). Persuasive systems design: Key issues, process model, and system features. Communications of the Association for Information Systems, vol. 24, no. 1, pp. 28.

O'Keefe, Daniel J. (2002). Persuasion: theory \& research. 2nd ed. Thousand Oaks, CA: Sage Pub.

Orlikowski, Wanda J. (2008). Using Technology and Constituting Structures: A Practice Lens for Studying Technology in Organizations. In Resources, Co-Evolution and Artifacts, pp. 255-305. London: Springer.

Orlikowski, Wanda J.; and C. Suzanne Iacono (2001). Research Commentary: Desperately Seeking the "IT" in IT Research-A Call to Theorizing the IT Artifact. Information Systems Research, vol. 12, no. 2, pp. 121-134.

Ozer, Elizabeth M.; and Albert Bandura (1990). Mechanisms governing empowerment effects: A self-efficacy analysis. Journal of Personality and Social Psychology, vol. 58, no. 3, pp. 472-486.

Park, Sunghyun; Han Suk Shim; Moitreya Chatterjee; Kenji Sagae; and LouisPhilippe Morency (2014). Computational Analysis of Persuasiveness in Social Multimedia: A Novel Dataset and Multimodal Prediction Approach. In A. A. Salah, J. Cohn, B. Schuller, O. Aran, L-P. Morency, P. R. Cohen (eds): Proceedings of the 16th International Conference on Multimodal Interaction, Istanbul, Turkey, 12 November - 16 November 2014. New York, USA: ACM Press, pp. 50-57.

Petty, Richard E. (2013). Two routes to persuasion: State of the art. International perspectives on psychological science, vol. 2, pp. 229-247.

Richter, Alexander; and Kai Riemer (2009). Corporate social networking sitesmodes of use and appropriation through co-evolution. In : ACIS 2009. Proceedings of the 20th Australasian Conference on Information Systems, Melbourne, Australia, 2 December - 4 December 2009. Atlanta: AIS, pp. 722 - 732 .

Salovaara, Antti; Kristina Höök; Keith Cheverst; Michael Twidale; Matthew Chalmers; and Corina Sas (2011). Appropriation and creative use: linking user studies and design. In D. Tan, B. Begole, W. A. Kellog (eds): CHI'11 Extended Abstracts on Human Factors in Computing Systems, Vancouver, Canada, 7 May - 12 May 2011. New York, USA: ACMPress, pp. 37-40.

Schegloff, Emanuel A. (1986). The Routine as Achievement. Human Studies, vol. 9, no. $2 / 3$, pp. 111-151. 
Schmidt, Kjeld (2011). Cooperative Work and Coordinative Practices. London: Springer.

Schmidt, Kjeld; and Liam Bannon (2013). Constructing CSCW: The First Quarter Century. Computer Supported Cooperative Work (CSCW), vol. 22, no. 4 6, pp. 345-372.

Schwabe, Gerhard; and Philipp Nussbaumer (2009). Why information technology is not being used for financial advisory. In ECIS 2009. Proceedings of the 17th European Conference on Information Systems, Verona, Italy, 8 June - 10 June 2009. Atlanta: AIS, pp. 450-462.

Scollon, Ronald (2001). Mediated discourse: the nexus of practice. London; New York: Routledge.

Simon, Herbert A. (1978). Rationality as Process and as Product of Thought. The American Economic Review, vol. 68, no. 2, pp. 1-16.

Simons, Herbert W.; and Jean Jones (2011). Persuasion in society. 2nd ed. New York, USA: Routledge.

Stevens, Gunnar; Volkmar Pipek; and Volker Wulf (2010). Appropriation Infrastructure: Mediating Appropriation and Production Work. Journal of Organizational and End User Computing, vol. 22, no. 2, pp. 58-81.

Stibe, Agnis (2015). Advancing Typology of Computer-Supported Influence: Moderation Effects in Socially Influencing Systems. In T. MacTavish, S. Basapur (eds): PERUASIVE 2015. Proceedings of the 10th International Conference on Persuasive Technology, Chicago, USA, 3 June - 5 June 2015. Cham, Switzerland: Springer Intl. Publishing.

Stibe, Agnis; and Harri Oinas-Kukkonen (2014). Designing Persuasive Systems for user engagement in collaborative interaction. In M. Avital, JM. Leimeister, U. Schultze (eds): ECIS 2014. Proceedings of the European Conference on Information Systems, Tel Aviv, Israel, 9 June - 11 June 2014. Atlanta: AIS, pp. 253-264.

Suchman, Lucille Alice (1987). Plans and situated actions: the problem of human-machine communication. Cambridge, New York: Cambridge University Press.

Svennevig, Jan (2001). Institutional and conversational modes of talk in bureaucratic consultations. In Meetings at the crossroads. pp. 106-135. Oslo: Novus.

Svinhufvud, Kimmo; and Sanna Vehviläinen (2013). Papers, documents, and the opening of an academic supervision encounter. Text \& Talk, vol. 33, no. 1, pp. 139-166.

Swindell, J. S.; Amy L. McGuire; and Scott D. Halpern (2010). Beneficent Persuasion: Techniques and Ethical Guidelines to Improve Patients' Decisions. Annals of Family Medicine, vol. 8, no. 3, pp. 260-264.

Vargo, Stephen L.; and Melissa Archpru Akaka (2012). Value Cocreation and Service Systems (Re)Formation: A Service Ecosystems View. Service Science, vol. 4, no. 3, pp. 207-217.

Ven, Andrew H. Van De; and Marshall Scott Poole (1995). Explaining Development and Change in Organizations. Academy of Management Review, vol. 20, no. 3, pp. 510-540. 
Wooffitt, Robin (2005). Conversation analysis and discourse analysis a comparative and critical introduction. London; Thousand Oaks, Calif.: SAGE.

Wulf, Volker; Markus Rohde; Volkmar Pipek; and Gunnar Stevens (2011). Engaging with practices: design case studies as a research framework in CSCW. In P. Hinds, JC. Tang, J. Wang, J. Bardram, N. Ducheneaut (eds): CSCW 2011. Proceedings of the ACM 2011 Conference on Computer Supported Cooperative Work, Hangzhou, China, 19 March - 23 March 2011. ACM Press: New York. pp. 505-512.

Yang, Diyi; and Robert E. Kraut (2017). Persuading Teammates to Give: Systematic Versus Heuristic Cues for Soliciting Loans. Proceedings of the ACM on Human-Computer Interaction, vol. 1, CSCW, pp. 114:1-114:21.

Yaniv, Ilan (2004a). The Benefit of Additional Opinions. Current Directions in Psychological Science, vol. 13, no. 2, pp. 75-78.

Yaniv, Ilan (2004b). Receiving other people's advice: Influence and benefit. Organizational Behavior and Human Decision Processes, vol. 93, no. 1, pp. 1-13.

Yaniv, Ilan; and Eli Kleinberger (2000). Advice Taking in Decision Making: Egocentric Discounting and Reputation Formation. Organizational Behavior and Human Decision Processes, vol. 83, no. 2, pp. 260-281.

Zucchermaglio, Cristina; Francesca Alby; and Marilena Fatigante (2016). What counts as illness? Anamnesis as a collaborative activity. TPM: Testing, Psychometrics, Methodology in Applied Psychology, vol. 23, no. 4, pp. 471-487. 